\title{
Cerium Oxide Nanoparticles Regulate Osteoclast Differentiation Bidirectionally by Modulating the Cellular Production of Reactive Oxygen Species
}

This article was published in the following Dove Press journal: International Journal of Nanomedicine

\author{
Kai Yuan ${ }^{1, *}$ \\ Jingtian Mei ${ }^{1, *}$ \\ Dandan Shao ${ }^{2}$ \\ Feng Zhou' \\ Han Qiao' \\ Yakun Liang ${ }^{3}$ \\ Kai Li (D) ${ }^{2}$ \\ Tingting Tang $\mathbb{D}^{\prime}$ \\ 'Shanghai Key Laboratory of Orthopedic \\ Implants, Department of Orthopedic \\ Surgery, Shanghai Ninth People's \\ Hospital, Shanghai Jiao Tong University \\ School of Medicine, Shanghai 2000II, \\ People's Republic of China; ${ }^{2}$ Key \\ Laboratory of Inorganic Coating \\ Materials, Shanghai Institute of Ceramics, \\ Chinese Academy of Sciences, Shanghai \\ 200050, People's Republic of China; \\ ${ }^{3}$ Shanghai Institute of Precision Medicine, \\ Shanghai 200I25, People's Republic of \\ China
}

*These authors contributed equally to this work

\section{Correspondence: Tingting Tang} Shanghai Key Laboratory of Orthopedic Implants, Department of Orthopedic Surgery,Shanghai Ninth People's Hospital, Shanghai Jiao Tong University School of

Medicine, Room 70I, No. 3 Building, 639

Zhizaoju Road, Shanghai 2000II, People's

Republic of China Tel/

Fax +86 21 63137020

Email ttt@sjtu.edu.cn

Kai Li

Key Laboratory of Inorganic Coating Materials, Shanghai Institute of Ceramics, Chinese Academy of Sciences, 1295

Dingxi Road, Shanghai 200050, People's

Republic of China Tel/

Fax +86 2I-524I3903

Email likai@mail.sic.ac.cn
Background: Cerium oxide nanoparticles $\left(\mathrm{CeO}_{2} \mathrm{NPs}\right)$ are potent scavengers of cellular reactive oxygen species (ROS). Their antioxidant properties make $\mathrm{CeO}_{2} \mathrm{NPs}$ promising therapeutic agents for bone diseases and bone tissue engineering. However, the effects of $\mathrm{CeO}_{2} \mathrm{NPs}$ on intracellular ROS production in osteoclasts (OCs) are still unclear. Numerous studies have reported that intracellular ROS are essential for osteoclastogenesis. The aim of this study was to explore the effects of $\mathrm{CeO}_{2} \mathrm{NPs}$ on osteoclast differentiation and the potential underlying mechanisms.

Methods: The bidirectional modulation of osteoclast differentiation by $\mathrm{CeO}_{2} \mathrm{NPs}$ was explored by different methods, such as fluorescence microscopy, scanning electron microscopy (SEM), transmission electron microscopy (TEM), quantitative real-time polymerase chain reaction (qRT-PCR), and Western blotting. The cytotoxic and proapoptotic effects of $\mathrm{CeO}_{2} \mathrm{NPs}$ were detected by cell counting kit (CCK-8) assay, TdT-mediated dUTP nick-end labeling (TUNEL) assay, and flow cytometry.

Results: The results of this study demonstrated that although $\mathrm{CeO}_{2} \mathrm{NPs}$ were capable of scavenging ROS in acellular environments, they facilitated the production of ROS in the acidic cellular environment during receptor activator of nuclear factor kappa-B ligand (RANKL)-dependent osteoclast differentiation of bone marrow-derived macrophages (BMMs). $\mathrm{CeO}_{2} \mathrm{NPs}$ at lower concentrations $(4.0 \mu \mathrm{g} / \mathrm{mL}$ to $8.0 \mu \mathrm{g} / \mathrm{mL})$ promoted osteoclast formation, as shown by increased expression of $\mathrm{Nfatcl}$ and $\mathrm{C}$-Fos, F-actin ring formation and bone resorption. However, at higher concentrations (greater than $16.0 \mu \mathrm{g} / \mathrm{mL}$ ), $\mathrm{CeO}_{2} \mathrm{NPs}$ inhibited osteoclast differentiation and promoted apoptosis of BMMs by reducing $\mathrm{Bcl} 2$ expression and increasing the expression of cleaved caspase-3, which may be due to the overproduction of ROS.

Conclusion: This study demonstrates that $\mathrm{CeO}_{2} \mathrm{NPs}$ facilitate osteoclast formation at lower concentrations while inhibiting osteoclastogenesis in vitro by inducing the apoptosis of BMMs at higher concentrations by modulating cellular ROS levels.

Keywords: cerium oxide nanoparticles, osteoclast, osteoclastogenesis, ROS, apoptosis

\section{Introduction}

As one of the lanthanide elements, cerium $(\mathrm{Ce})$ is the most abundant among the rare-earth elements. The metal oxide form of $\mathrm{Ce}$, cerium oxide, enables quick and regenerative redox cycling between two oxidation states, $\mathrm{Ce}^{3+}$ and $\mathrm{Ce}^{4+}$, due to the oxygen vacancies in its crystal lattice, which endows cerium oxide with robust catalytic activity. ${ }^{1}$ In addition, because of the high surface-volume ratio and monodispersion, an increased number of stable surface oxygen vacancies are found in 
cerium oxide nanoparticles $\left(\mathrm{CeO}_{2} \mathrm{NPs}\right)$ compared with those of cerium oxide bulk material when they reach the nanoscale (less than $100 \mathrm{~nm}$ ). ${ }^{2-4}$ Hence, the exposed surface oxygen vacancies in $\mathrm{CeO}_{2} \mathrm{NPs}$ act as reaction sites, facilitate redox cycling and enhance catalytic activity. $\mathrm{CeO}_{2} \mathrm{NPs}$ are multienzymes that possess catalasemimetic, ${ }^{5,6}$ superoxide dismutase-mimetic, ${ }^{7,8}$ peroxidasemimetic activities ${ }^{9}$ when applied in cell culture and animal experiments. In most reports, $\mathrm{CeO}_{2} \mathrm{NPs}$ scavenge reactive oxygen species (ROS), including hydrogen peroxide and free radicals, such as $\cdot \mathrm{OH}, \mathrm{O}^{2-}, \mathrm{NO}$, within the cellular environment, thus attenuating ROS production and organ dysfunction in ROS-related diseases, including myocardial damage, systemic inflammatory reaction syndrome, psoriasis and Alzheimer's disease. ${ }^{10-14}$ However, there are also other reports demonstrating that in some acidic environments, such as cancer cells, $\mathrm{CeO}_{2} \mathrm{NPs}$ exhibit oxidase-like activity, enhancing intracellular ROS production and cell toxicity. ${ }^{15-17}$

In recent years, many researchers have explored the application of $\mathrm{CeO}_{2} \mathrm{NPs}$ in bone regeneration and bone tissue engineering. Many researchers have focused on mesenchymal stem cells and osteogenesis. Previous studies demonstrated that $\mathrm{CeO}_{2} \mathrm{NPs}$ alone or $\mathrm{CeO}_{2} \mathrm{NPs}$ composed of implant coating and scaffolds facilitate cell viability and osteoblastic differentiation of bone mesenchymal stem cells (BMSCs) by scavenging ROS in the cell microenvironment. ${ }^{18-23}$ In this regard, $\mathrm{CeO}_{2} \mathrm{NPs}$ seem to have some promising effects on bone volume maintenance and bone defect repair. However, the effects of $\mathrm{CeO}_{2} \mathrm{NPs}$ on osteoclastogenesis have not yet been clearly explored. Few studies have focused on the effects of $\mathrm{CeO}_{2} \mathrm{NPs}$ on osteoclast (OC) formation. A previous report indicated that citrate-stabilized $\mathrm{CeO}_{2} \mathrm{NPs}$ at a concentration of $5 \mu \mathrm{M}$ facilitated receptor activator of nuclear factor kappa$\mathrm{B}$ ligand (RANKL)-dependent osteoclastogenesis by upregulating the expression of Tumor necrosis factor alpha (TNF- $\alpha$ ); however, this study did not detect intracellular ROS levels or relative pathway activation. ${ }^{24}$ Thus, it is important to clarify the effects of $\mathrm{CeO}_{2} \mathrm{NPs}$ on osteoclastogenesis for better evaluation of the practicability of $\mathrm{CeO}_{2} \mathrm{NP}$-related therapy.

Although excessive production of cellular ROS causes lipid peroxidation, protein denaturation, and nucleic acid damage, leading to cell apoptosis and death, increasing evidence confirms that physiological ROS levels play a crucial role in osteoclastogenesis. ${ }^{25-28}$ Osteoclasts are mainly derived from bone marrow-derived macrophages (BMMs). Under the stimulation of two indispensable factors for osteoclastogenesis, macrophage colony-stimulating factor (M-CSF) and RANKL, endogenous ROS production in BMMs is activated, followed by activation of downstream signaling pathways, including the mitogenactivated protein kinase (MAPK) pathway and NF- $\kappa B$ pathway, and ultimately contributes to BMMs fusion into large multinucleated mature osteoclasts. ${ }^{28-30}$ Lee, N. K found that ROS levels in BMMs were significantly elevated and peaked at $10 \mathrm{~min}$ after RANKL stimulation. After treatment with N-acetylcysteine (NAC), a chemical antioxidant, RANKL-stimulated ROS production in BMMs was significantly inhibited in a dose-dependent manner. ${ }^{25}$ In addition, accompanied by the fusion of BMMs, the expression of carbonic anhydrase II is also highly elevated, leading to acidification of osteoclasts and a reduced $\mathrm{pH}$ cellular environment, which enable the absorptive function of osteoclasts. ${ }^{31}$ Although previous studies have demonstrated that $\mathrm{CeO}_{2} \mathrm{NPs}$ scavenge ROS in macrophages in other organs, such as Kupffer cells, ${ }^{10}$ the ROS scavenging capability of $\mathrm{CeO}_{2} \mathrm{NPs}$ has not been elucidated in acidic osteoclasts.

Recent studies have demonstrated that the ROSscavenging ability of $\mathrm{CeO}_{2} \mathrm{NPs}$ was converted into oxidative activity in acidic environments, such as in comparatively acidic cancer cells. ${ }^{32-34}$ The redox cycle from $\mathrm{Ce}^{3+}$ to $\mathrm{Ce}^{4+}$ is blocked by excessive $\mathrm{H}^{+}$, resulting in blockade of catalytic activity and accumulation of $\mathrm{H}_{2} \mathrm{O}_{2}$ in the cellular microenvironment, ultimately leading to cell damage and dysfunction. ${ }^{35}$ Wason MS found that pretreatment with $10 \mu \mathrm{M} \mathrm{CeO}_{2} \mathrm{NPs}$ enhanced ROS production in response to radiation in acidic acellular medium and acidic pancreatic cancer cells. ${ }^{16}$ This suggests that $\mathrm{CeO}_{2} \mathrm{NPs}$, which are potent ROS scavengers, might demonstrate ROS-promoting effects during osteoclastogenesis.

In this study, we utilized $\mathrm{CeO}_{2} \mathrm{NPs}$ with an average diameter of $20 \mathrm{~nm}$ at different concentrations to investigate their potential regulatory effects on ROS production and signal transduction during osteoclastogenesis.

\section{Materials and Methods Characterization of $\mathrm{CeO}_{2} \mathrm{NPs}$}

$\mathrm{CeO}_{2} \mathrm{NPs}$ were purchased from Engi-Mat (Lexington, Kentucky, USA). The purity of the cerium oxide nanoparticles was greater than $99.9 \%$. The crystallinity was determined by X-ray diffraction (XRD, Rigaku Corporation, RigakuD/Max-2200 PC, Japan). The surface chemical composition and valence state of $\mathrm{CeO}_{2} \mathrm{NPs}$ were determined by $\mathrm{X}$-ray photoelectron spectroscopy (XPS, Thermo Scientific, 
ESCALAB 250, USA). The crystal structure and size were observed by transmission electron microscopy (TEM, Thermo Scientific, FEI Talos L120C, USA). The crystal size observed by XRD was calculated according to the Scherrer equation. ${ }^{36}$

\section{Electron Spin Resonance (ESR)}

An ESR paramagnetic spectrometer (JEOL, JEOL-FA200, Japan) was used to detect the ROS scavenging ability of $\mathrm{CeO}_{2} \mathrm{NPs}$ in the acellular environment according to the manufacturer's instructions for 5,5'-dimethylpyrroline N-oxide (DMPO, Dojindo, Japan). For hydroxyl radical scavenging measurements, $\mathrm{CeO}_{2} \mathrm{NPs}$ at a final concentration of $256 \mathrm{mg} / \mathrm{L}$ were incubated with $100 \mathrm{mM}$ DMPO, $0.05 \mathrm{U} / \mathrm{mL}$ xanthine oxidase (Solarbio Life Science, China) and $0.5 \mathrm{mM}$ hypoxanthine (Solarbio Life Science, China) in water for $1 \mathrm{~min}$, and then hydroxyl radicals were determined by ESR. To induce superoxide radicals for scavenging measurement, $\mathrm{CeO}_{2} \mathrm{NPs}$ at a final concentration of $256 \mathrm{mg} / \mathrm{L}$ were incubated with $100 \mathrm{mM}$ DMPO, $0.05 \mathrm{U} / \mathrm{mL}$ xanthine oxidase, $0.5 \mathrm{mM}$ hypoxanthine, in $100 \%$ ethanol for $1 \mathrm{~min}$, and then the level of $\mathrm{O}^{2-}$ was determined by ESR.

\section{Cell Culture}

BMMs were isolated as previously described. ${ }^{37} \mathrm{C} 57 \mathrm{BL} / 6$ mice (4-week-old, male) were purchased from Shanghai SIPPR-Bk Lab Animal Company. All animal experiments were approved by the Animal Ethical Committee of Shanghai Ninth People's Hospital. In brief, all mice were sacrificed by cervical dislocation, then tibiae and femora were harvested. Bone marrow cells were rinsed, added to culture plate and then cultured in $\alpha$-MEM medium (HyClone, USA) containing 10\% fetal bovine serum (Gibco, USA), 1\% penicillin-streptomycin solution (HyClone, USA) and $30 \mathrm{ng} / \mathrm{mL}$ M-CSF (R\&D, USA) at $5 \% \mathrm{CO}_{2}$ and $37{ }^{\circ} \mathrm{C}$ for 6 days. The culture medium containing M-CSF (30 ng/mL) was replaced every 2 days. For $\mathrm{CeO}_{2} \mathrm{NP}$ treatment, $\mathrm{CeO}_{2} \mathrm{NPs}$ were dispersed in sterile double distilled water $\left(\mathrm{ddH}_{2} \mathrm{O}\right)$ and treated with ultrasonic treatment for $10 \mathrm{~min}$ before being added to the culture medium.

\section{Cellular Internalization of $\mathrm{CeO}_{2} \mathrm{NPs}$}

Cellular internalization of $\mathrm{CeO}_{2} \mathrm{NPs}$ was observed by TEM (FEI Talos L120C, Thermo Scientific, USA). Briefly, BMMs were treated with various concentrations of $\mathrm{CeO}_{2} \mathrm{NPs}$ for the indicated times, fixed with $2.5 \%$ glutaraldehyde and 4\% osmic acid and dehydrated in graded ethanol. Then, the cells were permeated with resin and polymerized with a resin column at $65{ }^{\circ} \mathrm{C}$ for 2 days. After this, resin columns were sliced, stained and observed by TEM.

\section{Cell Viability Assay}

The cell viability of BMMs that were treated with $\mathrm{CeO}_{2}$ NPs was determined using a Cell Counting Kit (CCK-8, Dojindo Laboratories, Japan) assay. Cells were seeded in 96-well culture plates at a density of $1 \times 10^{4}$ cells per well. After incubating with different concentrations of $\mathrm{CeO}_{2} \mathrm{NPs}$ for $24 \mathrm{~h}, 48 \mathrm{~h}, 72 \mathrm{~h}$, and $120 \mathrm{~h}$, the medium was replaced with fresh culture medium containing 1/10 (v/v) CCK-8 solution and further incubated at $37^{\circ} \mathrm{C}$ for $3 \mathrm{~h}$. Then, the absorbance was measured at $450 \mathrm{~nm}$ using a microplate reader (Tecan, M200pro, Switzerland).

\section{Tartrate-Resistant Acid Phosphatase (TRAP) Staining Assay}

BMMs were seeded in 96-well culture plates $\left(1 \times 10^{4}\right.$ cells per well) and incubated with $\alpha$-MEM medium containing M-CSF $(30 \mathrm{ng} / \mathrm{mL})$ for $24 \mathrm{~h}$. The cells were pretreated with different concentrations of $\mathrm{CeO}_{2} \mathrm{NPs}$ for another $24 \mathrm{~h}$. Subsequently, the culture medium was replaced with fresh culture medium containing M-CSF (30 ng/mL) and RANKL $(50 \mathrm{ng} / \mathrm{mL})$, and the cells were incubated for 6 days. $^{37}$ The culture medium containing M-CSF, RANKL and different concentrations of $\mathrm{CeO}_{2} \mathrm{NPs}$ was replaced every 2 days. On day 4 , the cells were fixed in $4 \%$ paraformaldehyde solution at $37^{\circ} \mathrm{C}$ for $20 \mathrm{~min}$ and then stained with a TRAP staining kit (Sigma-Aldrich, USA) according to the manufacturer's procedures. After staining, the number and area of TRAP + osteoclasts containing 3 or more nuclei were observed by open-field microscopy (Olympus, IX71, Japan) and analyzed by ImageJ software (NIH, Bethesda, Maryland, USA).

\section{Actin Ring Formation Assay}

BMMs were seeded in 96-well culture plates $\left(1 \times 10^{4}\right.$ per well), cultured in complete $\alpha$-MEM medium and treated with different concentrations of $\mathrm{CeO}_{2} \mathrm{NPs}$ in the presence of M-CSF and RANKL for 6 days. After this, the cells were fixed in 4\% paraformaldehyde solution for $1 \mathrm{~h}$ and washed with PBS 3 times. Then, the cells were stained with rhodamine-conjugated phalloidin (Abcam, UK) for $30 \mathrm{~min}$ and subsequently stained with 4',6-diamidino-2-phenylindole 
(DAPI, Sigma-Aldrich, USA) for $10 \mathrm{~min}$ and washed with PBS 3 times. Finally, the actin rings were observed and imaged using a fluorescence microscope (Olympus, IX71, Japan).

\section{Bone Resorption Assay}

The bovine bone slices were sterilized by ethylene oxide sterilization and then soaked in culture medium in a 96-well culture plate for $24 \mathrm{~h}$ to remove residual ethylene oxide. Then, BMMs $\left(1 \times 10^{4}\right.$ cells per well $)$ were seeded on the bovine bone slices and were pretreated with different concentrations of $\mathrm{CeO}_{2} \mathrm{NPs}(0,4,8,16$, and $32 \mathrm{mg} / \mathrm{L})$. After this, the cells were cultured in the presence of M-CSF (30 $\mathrm{ng} / \mathrm{mL}$ ) and RANKL (50 ng/mL) for 2 weeks. The culture medium containing different concentrations of $\mathrm{CeO}_{2} \mathrm{NPs}$, M-CSF and RANKL was replaced every 2 days. After 2 weeks, the cells on the slices were removed using $0.25 \%$ EDTA-Trypsin, and the bone slices were dehydrated by gradient dehydration and then coated with gold for observation under a scanning electron microscope (SEM, HITACHI, S4800, Japan). ${ }^{37}$

\section{Intracellular $\mathrm{pH}$ Measurement}

The intracellular $\mathrm{pH}$ of BMMs and osteoclasts was measured using a $\mathrm{pH}$-sensitive fluorescent probe, 2',7'-bis -(2-carboxyethyl)-5-(and-6)-carboxyfluorescein, acetoxymethyl ester (BCECF-AM, Beyotime Biotechnology, China) and the nigericin calibration method. ${ }^{38}$ Briefly, BMMs were seeded in flat clear-bottom black 96-well microplates (Corning, USA) at a density of $2 \times 10^{4}$ cells per well and pretreated with various concentrations of $\mathrm{CeO}_{2} \mathrm{NPs}$ for $24 \mathrm{~h}$. Then, the cells were stimulated with M-CSF (30 $\mathrm{ng} / \mathrm{mL})$ and RANKL $(50 \mathrm{ng} / \mathrm{mL})$ for 2 or 4 days. On day 2 or day 4, the cells were washed with Hanks balanced salt solution (HBSS) 3 times and then incubated in HBSS with $3 \mu \mathrm{M}$ BCECF-AM at $37{ }^{\circ} \mathrm{C}$ in $5 \% \mathrm{CO}_{2}$ for $30 \mathrm{~min}$. Then, the cells were washed with prewarmed HBSS at pH 7.0 3 times. The fluorescence was determined using a microplate reader (Tecan, M200pro, Switzerland) with an emission wavelength of $535 \mathrm{~nm}$ and dualexcitation wavelengths of $490 \mathrm{~nm}$ and $430 \mathrm{~nm}$. BMMs were also calibrated in $\mathrm{Na}^{+}$-free calibration solution (135 $\mathrm{mM} \mathrm{KCl}, 2 \mathrm{mM} \mathrm{K} \mathrm{HPO}_{2}, 20 \mathrm{mM}$ HEPES, $1.2 \mathrm{mM} \mathrm{CaCl}_{2}$, $0.8 \mathrm{mM} \mathrm{MgSO}_{4}$, and $10 \mu \mathrm{M}$ nigericin) with different $\mathrm{pH}$ values $(5.5,6.0,6.5,7.0,7.5$, and 8.0) 5 times, and dualexcitation fluorescence measurements were performed to obtain a standard curve. Intracellular $\mathrm{pH}\left(\mathrm{pH}_{\mathrm{i}}\right)$ was calculated according to the standard curve.

\section{Quantitative Real-Time Polymerase Chain Reaction (qRT-PCR)}

qRT-PCR was performed as previously described. ${ }^{39}$ BMMs were cultured in 6 -well culture plates $\left(3 \times 10^{5}\right.$ cells per well) and pretreated with various concentrations of $\mathrm{CeO}_{2} \mathrm{NPs}$ for $24 \mathrm{~h}$. Then, the cells were stimulated with M-CSF (30 ng/mL) and RANKL (50 ng/mL) for 3 days. Total RNA from BMMs was isolated using Trizol reagent (Life Technologies, USA), and $1 \mu \mathrm{g}$ of total RNA template was transcribed into cDNA using All-in-One cDNA Synthesis SuperMix (Bimake, USA). Real-time PCR was performed by using SYBR Green qPCR Master Mix (Bimake, USA) on a Real-Time PCR platform (Applied Biosystems, ABI 7500, USA). All genes measured were normalized to beta-actin and calculated by the $2^{-\Delta \Delta \mathrm{Ct}}$ method. The primers we used for analysis are listed in Table 1.

\section{Western Blotting}

Western blotting was performed as previously described. ${ }^{40}$ BMMs were seeded in 6-well culture plates $\left(8 \times 10^{5}\right.$ cells per well) overnight. The cells were administered different concentrations of $\mathrm{CeO}_{2} \mathrm{NPs}$ and subsequently cultured in the presence or absence of RANKL for the indicated times. After this, the cells were washed once with PBS, lysed in cold SDS lysis buffer containing $1 \mathrm{mM}$ phenylmethanesulfonyl fluoride (PMSF, Beyotime Biotechnology, China) and phosphatase inhibitors (Bimake, USA), and centrifuged at 12,000 $\mathrm{rcf}$ for $10 \mathrm{~min}$. The total protein concentration was determined using a BCA protein assay kit (Beyotime Biotechnology, China). An equal amount of protein $(20 \mu \mathrm{g})$ was separated by SDSpolyacrylamide gel electrophoresis (SDS-PAGE) and transferred to a polyvinylidene fluoride membrane (Millipore, USA). The membrane was blocked in 5\% skim milk, incubated in primary antibody solution overnight, incubated in appropriate secondary antibody and detected by an infrared imaging system (Odyssey, USA). For P38, ERK, and JNK detection, the same membrane was probed for p-P38, p-ERK, and $\mathrm{p}-\mathrm{JNK}$, stripped and reincubated. The primary antibodies used were as follows: Nfatc1 (Santa Cruz Biotechnology, sc7294, USA, 1:1000), p-Nfatc1 (Affinity Biosciences, AF8012, USA, 1:1000), GAPDH (Affinity Biosciences, AF7021, USA, 1:1000), Lamin B1 (Cell Signaling Technology, 13,435, USA, 1:1000), p-ERK (Cell Signaling Technology, 4370, USA, 1:1000), ERK (Cell Signaling Technology, 4695, USA, 1:1000), p-JNK (Cell Signaling Technology, 4668, USA, 1:1000), JNK (Cell Signaling Technology, 9252, 
Table I Primer Sequences for qRT-PCR

\begin{tabular}{|l|l|l|}
\hline Gene & Forward Primer Sequence (5'-3') & Reverse Primer Sequence (5'-3') \\
\hline Acp5 & CACTCCCACCCTGAGATTTGT & CATCGTCTGCACGGTTCTG \\
Ctsk & GGACCCATCTCTGTGTCCAT & CCGAGCCAAGAGAGCATATC \\
C-Fos & CCAGTCAAGAGCATCAGCAA & AAGTAGTGCAGCCCGGAGTA \\
Calcr & CGGACTTTGACACAGCAGAA & AGCAGCAATCGACAAGGAGT \\
Trafb & AAACCACGAAGAGGTCATGG & GCGGGTAGAGACTTCACAGC \\
Dcstamp & AAAACCCTTGGGCTGTTCTT & AATCATGGACGACTCCTTGG \\
Bcl2 & ATGCCTTTGTGGAACTATATGGC & GGTATGCACCCAGAGTGATGC \\
Bax & TGAAGACAGGGGCCTTTTTG & AATTCGCCGGAGACACTCG \\
Bad & AAGTCCGATCCCGGAATCC & GCTCACTCGGCTCAAACTCT \\
Ca2 & TCCCACCACTGGGGATACAG & CTCTTGGACGCAGCTTTATCATA \\
Beta-actin & AGAGGGAAATCGTGCGTGACA & CACTGTGTTGGCATAGAGGTC \\
\hline
\end{tabular}

Abbreviations: Acp5, acid phosphatase 5; Ctsk, cathepsin K; C-Fos, proto-oncogene C-Fos; Calcr, calcitonin receptor; Traf6, TNF receptor-associated factor 6; Dcstamp, dendrocyte expressed seven transmembrane protein; Bcl2, BCL2 apoptosis regulator; Bax, $\mathrm{BCL2}$-associated X, apoptosis regulator; Bad, BCL2-associated agonist of cell death; Ca2, carbonic anhydrase 2.

USA, 1:1000), p-P38 (Cell Signaling Technology, 4092, USA, 1:1000), P38 (Cell Signaling Technology, 9212, USA, 1:1000), p-IKK $\alpha / \beta$ (Cell Signaling Technology, 2697, USA, 1:1000), IKK $\alpha$ (Cell Signaling Technology, 2682, USA, 1:1000), p-IKB $\alpha$ (Cell Signaling Technology, 2859, USA, 1:1000), IKB $\alpha$ (Cell Signaling Technology, 4812, USA, 1:1000), p-P65 (Cell Signaling Technology, 3033, USA, 1:1000), P65 (Cell Signaling Technology, 8242, USA, 1:1000), Bcl2 (Abcam, ab32124, UK, 1:1000), cleavedCaspase3 (Cell Signaling Technology, 9661, USA, 1:1000), Caspase3 (Cell Signaling Technology, 9662, USA, 1:1000), and $\beta$-Actin (Cell Signaling Technology, 4970, USA, 1:1000).

\section{Intracellular ROS Assay}

Intracellular ROS production was determined as previously described. ${ }^{25}$ Briefly, BMMs were seeded in $35 \mathrm{~mm}$ dishes, pretreated with different concentrations of $\mathrm{CeO}_{2} \mathrm{NPs}$ for $24 \mathrm{~h}$ and then stimulated with RANKL $(50 \mathrm{ng} / \mathrm{mL})$ and $\mathrm{M}-\mathrm{CSF}(30 \mathrm{ng} / \mathrm{mL})$ for the indicated times. For ROS detection, the cells were washed with PBS 3 times. Then, the cells were probed with $10 \mu \mathrm{M}$ DCFH-DA (Beyotime Biotechnology, China) dissolved in HBSS for $30 \mathrm{~min}$ and washed 3 times. Then, the cells were observed under a laser confocal scanning microscope (LCSM, Leica, Germany). For early-stage ROS measurement, BMMs were pretreated with various concentrations of $\mathrm{CeO}_{2} \mathrm{NPs}$ and probed with $10 \mu \mathrm{M}$ DCFH-DA for $30 \mathrm{~min}$. Then, the cells were transferred from the plate to sterile tubes with $0.25 \%$ EDTA-free trypsin, stimulated with HBSS containing $30 \mathrm{ng} / \mathrm{mL}$ RANKL for $10 \mathrm{~min}$ and immediately subjected to flow cytometry on a flow cytometer (BD Bioscience, LSRFortessa, USA). The fluorescence of DCF was measured with an excitation wavelength of $488 \mathrm{~nm}$ with an emission wavelength ranging from $515 \mathrm{~nm}$ to $540 \mathrm{~nm}$.

\section{In vitro TUNEL Assay}

BMM apoptosis was determined by using a One-Step TUNEL Assay Kit (Beyotime Biotechnology, C1086, China) according to the manufacturer's procedures. Briefly, BMMs were seeded in $35 \mathrm{~mm}$ confocal dishes and pretreated with various concentrations of $\mathrm{CeO}_{2} \mathrm{NPs}$ for 48 h. Then, the cells were washed once with PBS and fixed with 4\% paraformaldehyde for $1 \mathrm{~h}$. After this, PBS with $0.3 \%$ Triton X-100 was used to permeabilize the cells. Then, the cells were incubated in TUNEL staining solution for $1 \mathrm{~h}$ and subsequently stained with DAPI solution. Finally, the cells were washed with PBS 3 times and observed under a laser confocal scanning microscope (LCSM, Leica, Germany). For TUNEL detection, the excitation wavelength and the emission wavelength were set at $488 \mathrm{~nm}$ and $520 \mathrm{~nm}$, respectively. For DAPI detection, the excitation wavelength and the emission wavelength were set at $400 \mathrm{~nm}$ and $488 \mathrm{~nm}$, respectively.

\section{Flow Cytometry to Analyze BMM Apoptosis}

BMMs were seeded in 6 -well culture plates $\left(5 \times 10^{5}\right.$ cells per well) and treated with various concentrations of $\mathrm{CeO}_{2}$ NPs, M-CSF (30 ng/mL) and RANKL (50 ng/mL) for 48 h. Then, BMMs were collected using EDTA-free trypsin and stained with Annexin V-FITC/propidium iodide (PI) double (BD Bioscience, USA) according to the manufacturer's procedures. After this, the cell suspension was 
subjected to flow cytometry on a flow cytometer (BD Bioscience, LSR Fortessa, USA).

\section{Statistical Analysis}

All data in the experiments were analyzed with SPSS 13.0 software (Statistical Package for the Social Sciences, USA) and are presented as the means \pm standard deviation. We used one-way analysis of variance (ANOVA) followed by a Tukey's test to compare multigroup parametric data. The level of statistical significance was set at $\mathrm{P}<0.05$. \# and * indicate $\mathrm{P}<0.05$ when comparing the control group with the vehicle group and the treated groups with the vehicle groups, respectively. \#\# and $* *$ indicate $\mathrm{P}<0.01$ when comparing the control group with the vehicle group and the treated groups with the vehicle groups, respectively.

\section{Results}

\section{Characterization of $\mathrm{CeO}_{2} \mathrm{NPs}$}

The morphology and size of $\mathrm{CeO}_{2} \mathrm{NPs}$ were observed by TEM. Figure $1 \mathrm{~A}$ showed that $\mathrm{CeO}_{2} \mathrm{NPs}$ presented a cubic structure. Figure 1B demonstrated that the diameter of $\mathrm{CeO}_{2} \mathrm{NPs}$ ranged from $5 \mathrm{~nm}$ to $35 \mathrm{~nm}$, with a mean diameter of $17 \mathrm{~nm}$. XPS results (Figure 1C-E) showed that the relative levels of $\mathrm{Ce}^{4+}, \mathrm{Ce}^{3+}$, and oxygen vacancies were $73 \%, 27 \%$, and $19.67 \%$, respectively. XRD measurements (Figure 1F) further validated the size distribution of $\mathrm{CeO}_{2} \mathrm{NPs}$, with a 23.8 $\mathrm{nm}$ mean Scherrer diameter. These results suggest that the $\mathrm{CeO}_{2} \mathrm{NPs}$ used in this experiment had a relatively high $\mathrm{Ce}^{4+}$ content and oxygen vacancies and might be a possible ROS scavenger.

\section{ROS Scavenging Ability of $\mathrm{CeO}_{2} \mathrm{NPs}$ in an Acellular Environment}

To validate the ROS scavenging ability of $\mathrm{CeO}_{2} \mathrm{NPs}$, we used ESR to test the hydroxyl radical and superoxide radical scavenging ability of $\mathrm{CeO}_{2} \mathrm{NPs}$. Xanthine oxidase oxidizes hypoxanthine and generates hydroxyl radicals and superoxide radicals in water and ethanol solutions, respectively. In contrast to the blank control without $\mathrm{CeO}_{2} \mathrm{NPs}$, $\mathrm{CeO}_{2} \mathrm{NPs}(256 \mathrm{mg} / \mathrm{L})$ effectively reduced the peak amplitude of ESR signals of the hydroxyl radical (59\%) and superoxide radical (35\%) (Figure $1 \mathrm{G}$ and $\mathrm{H}$ ). These results suggest that $\mathrm{CeO}_{2} \mathrm{NPs}$ attenuate ROS production in acellular HX/XO systems.

\section{Effects of $\mathrm{CeO}_{2} \mathrm{NPs}$ on the Viability of BMMs}

To determine the cell viability and proliferation of BMMs at various concentrations of $\mathrm{CeO}_{2} \mathrm{NPs}$, we used the CCK-8 assay in this experiment (Figure $2 \mathrm{~A}$ ). $\mathrm{CeO}_{2} \mathrm{NPs}$ showed no evident cytotoxic effects on cell viability or proliferation until reaching a threshold of $128 \mathrm{mg} / \mathrm{L}$ after 1 and 2 days. And $\mathrm{CeO}_{2} \mathrm{NPs}$ showed cytotoxic effects on BMMs when the concentration of $\mathrm{CeO}_{2} \mathrm{NPs}$ was above $64 \mathrm{mg} / \mathrm{L}$ after 3 and 5 days. Due to this result, the concentrations of $\mathrm{CeO}_{2}$ NPs used to pretreat the BMMs were no greater than $64 \mathrm{mg} /$ L. These results also indicate that $\mathrm{CeO}_{2} \mathrm{NPs}$ are a potential biocompatible nanomedicine or delivery tool.

\section{Cellular Internalization of $\mathrm{CeO}_{2} \mathrm{NPs}$}

Cellular internalization of $\mathrm{CeO}_{2} \mathrm{NPs}$ was observed by TEM. As shown in Figure 2B, after treatment with $\mathrm{CeO}_{2}$ NPs for $24 \mathrm{~h}, \mathrm{CeO}_{2} \mathrm{NPs}$ that were internalized by BMMs were found mainly in the cytoplasm and lysosomes (Figure 2C). Most cells in the 8 and $16 \mathrm{mg} / \mathrm{L} \mathrm{CeO}_{2} \mathrm{NPs}$ groups maintained normal cellular morphology. However, in the $64 \mathrm{mg} / \mathrm{L} \mathrm{CeO}_{2} \mathrm{NPs}$ group, some cells were filled with a large number of $\mathrm{CeO}_{2} \mathrm{NPs}$, and normal structure of other organelles was absent in these cells (Figure 2B). We also found that $\mathrm{CeO}_{2} \mathrm{NPs}$ entered the nucleus and disrupted the integrity of the cell membrane and organelles (Figure 2C). These results indicate that $\mathrm{CeO}_{2} \mathrm{NPs}$ are internalized by BMMs and distributed in the cytoplasm, lysosomes and nucleus. In addition, relatively high concentrations of $\mathrm{CeO}_{2} \mathrm{NPs}$ resulted in the destruction of cellular structure.

\section{$\mathrm{CeO}_{2} \mathrm{NPs}$ Modulate RANKL-Dependent Osteoclast Formation in a Bidirectional Manner}

The effects of $\mathrm{CeO}_{2} \mathrm{NPs}$ on osteoclast formation were measured using the TRAP staining assay. After pretreatment with various concentrations $(0,4,8,16,32$, and $64 \mathrm{mg} / \mathrm{L})$ of $\mathrm{CeO}_{2}$ NPs, BMMs were cultured in the presence of M-CSF (30 ng/ $\mathrm{mL})$ and RANKL $(50 \mathrm{ng} / \mathrm{mL})$ for 4 days until TRAP staining. Figure $3 \mathrm{~A}$ demonstrates that $\mathrm{CeO}_{2} \mathrm{NPs}$ treatment facilitated RANKL-dependent osteoclast formation at lower concentrations $(4.0 \mathrm{mg} / \mathrm{L}$ to $8.0 \mathrm{mg} / \mathrm{L})$, with an increased average size of the formed osteoclasts. However, at higher concentrations $(16.0 \mathrm{mg} / \mathrm{L}$ to $64 \mathrm{mg} / \mathrm{L})$, we observed inhibitory effects of $\mathrm{CeO}_{2} \mathrm{NPs}$ on osteoclast formation. The average number and area were also counted. Figure $3 \mathrm{~B}$ and $\mathrm{C}$ show that the 
A
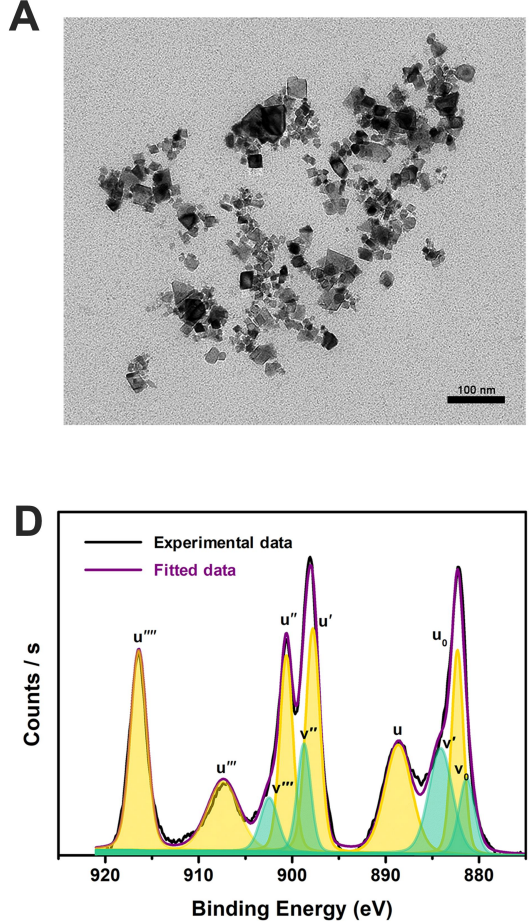

B

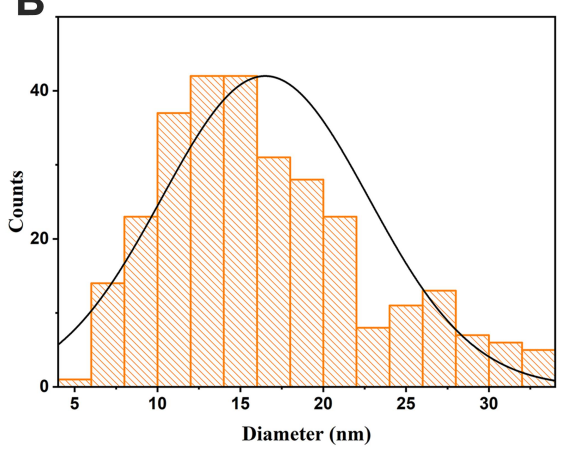

E

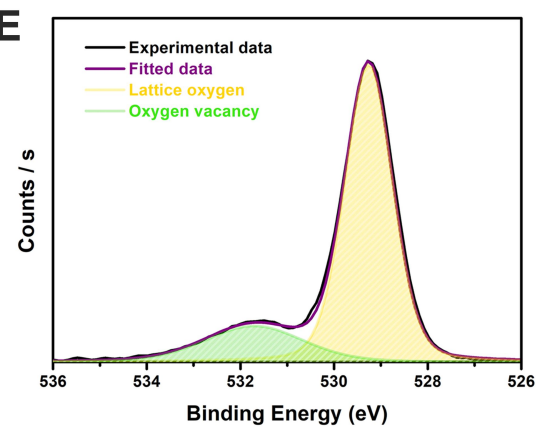

H

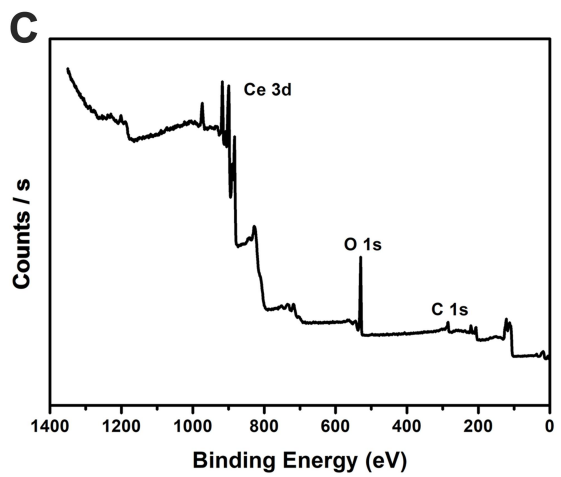

G

HX/XO (ethanol)

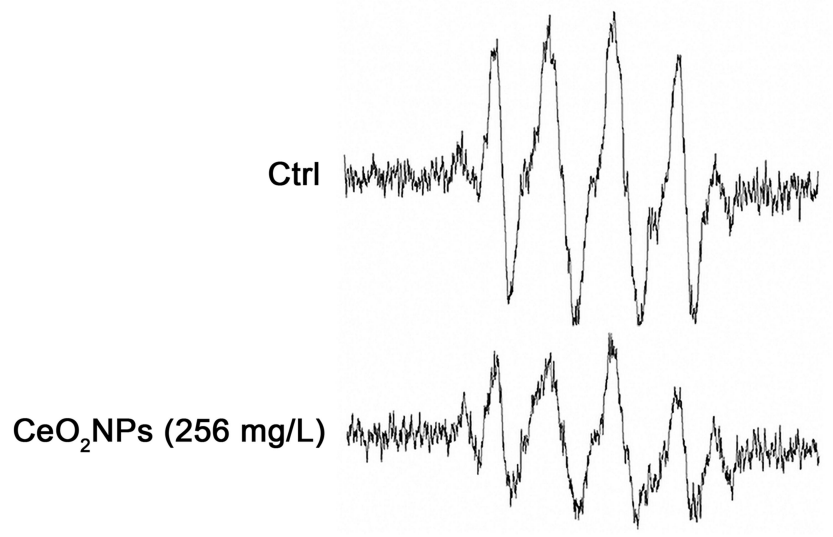

$\mathrm{CeO}_{2} \mathrm{NPs}(256 \mathrm{mg} / \mathrm{L})$

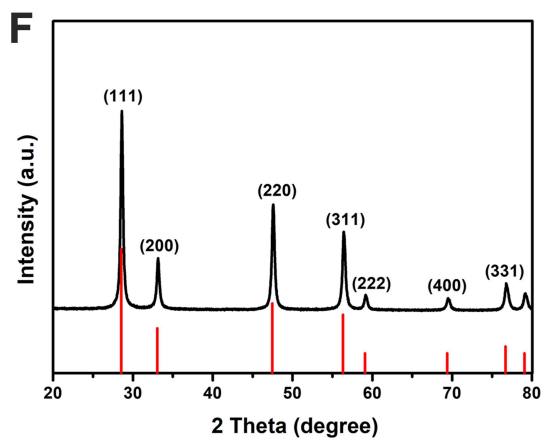

HX/XO (water)

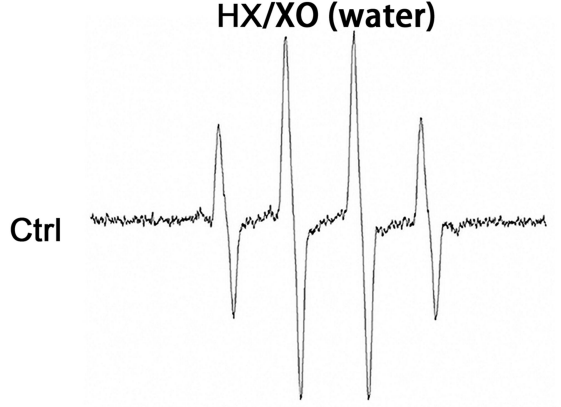

Figure I Characterization of $\mathrm{CeO}_{2} \mathrm{NPs}$ and the ROS scavenging ability of $\mathrm{CeO}_{2} \mathrm{NPs}$ in acellular environments.

Notes: (A) Morphology of $\mathrm{CeO}_{2}$ NPs was observed by TEM. Scale bar $=100 \mathrm{~nm}$ (B) Size distribution of $\mathrm{CeO}_{2} \mathrm{NPs}$ was measured by TEM. (C) Full XPS spectra of CeO ${ }_{2} \mathrm{NPs}$. (D) Development of $\mathrm{Ce} 3 \mathrm{~d}$ XPS spectra and fitted $\mathrm{Ce} 3 \mathrm{~d}$ XPS spectra. (E) Analysis results of the relative content of oxygen vacancies. (F) XRD pattern of CeO ${ }_{2} \mathrm{NPs}$. (G) Superoxide radicals that were generated by $0.5 \mathrm{mM}$ hypoxanthine and $0.05 \mathrm{U} / \mathrm{mL}$ xanthine oxidase in ethanol solution and superoxide radicals that were scavenged by $256 \mathrm{mg} / \mathrm{L} \mathrm{CeO}{ }_{2} \mathrm{NPs}$. $(\mathbf{H})$ $\mathrm{Hydroxyl}$ radicals that were generated by $0.5 \mathrm{mM}$ hypoxanthine and $0.05 \mathrm{U} / \mathrm{mL}$ xanthine oxidase in water solution and hydroxyl radicals that were scavenged by $256 \mathrm{mg} / \mathrm{L} \mathrm{CeO} \mathrm{NPs}_{2}$ Abbreviations: $\mathrm{HX}$, hypoxanthine; $\mathrm{XO}$, xanthine oxidase.

average number of multinucleated osteoclasts ( $>3$ nuclei) per field increased from 35.6 at $4 \mathrm{mg} / \mathrm{L}$ and slightly decreased to 23.3 at $8 \mathrm{mg} / \mathrm{L}$, followed by a declining trend from 33 to 14.6 when the $\mathrm{CeO}_{2} \mathrm{NPs}$ concentration increased from $16 \mathrm{mg} / \mathrm{L}$ to $64 \mathrm{mg} / \mathrm{L}$. Additionally, $\mathrm{CeO}_{2} \mathrm{NPs}$ increased the size of differentiated OCs from 1.0-fold (control) to 2.3 -fold $(4 \mathrm{mg} / \mathrm{L})$ and 6.20 -fold $(8 \mathrm{mg} / \mathrm{L})$ and subsequently inhibited the size of OCs from 2.4-fold (16 mg/L) to 1.4 -fold $(32 \mathrm{mg} / \mathrm{L})$ and 0.42 -fold $(64 \mathrm{mg} / \mathrm{L})$ in a dose-dependent manner. These results demonstrate that $\mathrm{CeO}_{2} \mathrm{NPs}$ modulate RANKL-dependent osteoclast formation in a bidirectional manner.

\section{Bidirectional Effects of $\mathrm{CeO}_{2} \mathrm{NPs}$ on Actin Ring Formation}

Under RANKL stimulation, BMMs differentiate into mature OCs, which are able to resorb bone matrix. We investigated the effects of $\mathrm{CeO}_{2} \mathrm{NPs}$ at the former concentrations on actin ring formation. As shown in Figure 3D-F, stimulation with 


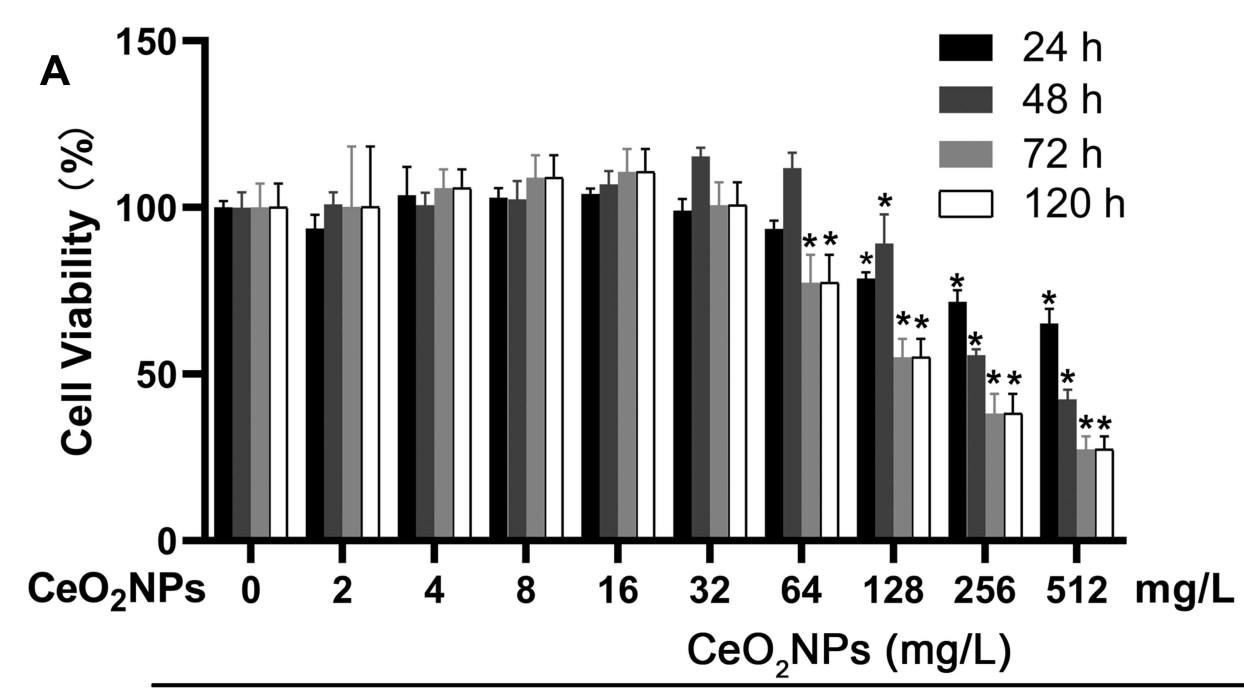

B

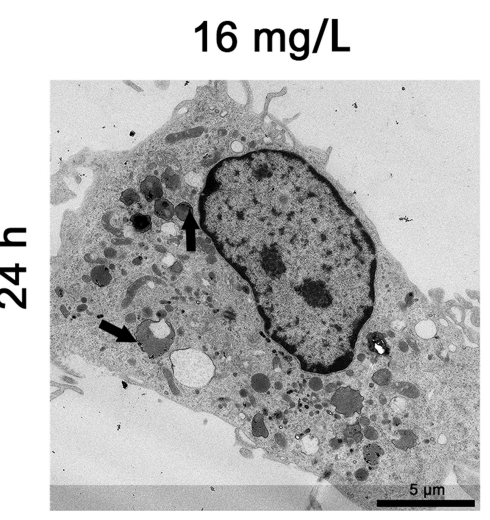

$32 \mathrm{mg} / \mathrm{L}$

$64 \mathrm{mg} / \mathrm{L}$

C
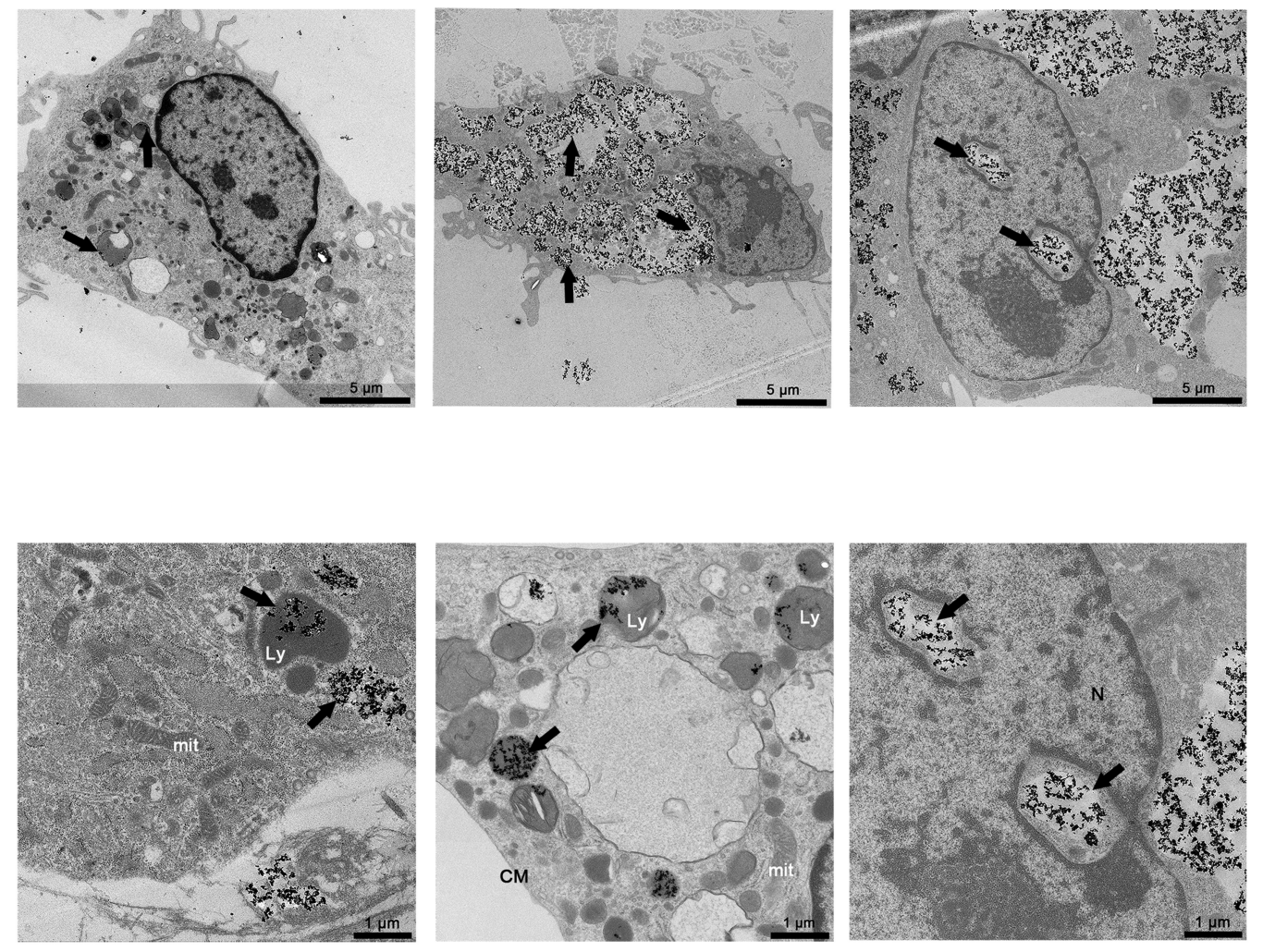

Figure 2 Effects of $\mathrm{CeO}_{2} \mathrm{NPs}$ on cell viability of $\mathrm{BMMs}$ and $\mathrm{CeO}_{2} \mathrm{NP}$ internalization by BMMs.

Notes: (A) Cell viability of BMMs that were treated with various concentrations of $\mathrm{CeO}_{2} \mathrm{NPs}$ for $24 \mathrm{~h}, 48 \mathrm{~h}, 72 \mathrm{~h}, 120 \mathrm{~h}$ was measured by CCK-8 assay. (B) Representative low-magnification TEM images of BMMs that were treated with 16, 32, and $64 \mathrm{mg} / \mathrm{L} \mathrm{CeO}{ }_{2} \mathrm{NPs}$ for $24 \mathrm{~h}$. Scale bar $=5 \mu \mathrm{M}$. (C) Representative high-magnification TEM images of the intracellular distribution of $\mathrm{CeO}_{2} \mathrm{NPs}$ in the cytoplasm, lysosome, and nucleus. Scale bar $=1 \mu \mathrm{M} . \mathrm{CeO}_{2} \mathrm{NPs}$ are indicated by black arrows. *Indicates $\mathrm{p}<0.05$ compared with the control group (0 mg/L, RANKL-).

Abbreviations: mit, mitochondria; Ly, lysosome; CM, cell membrane; N, nucleus.

$\mathrm{CeO}_{2} \mathrm{NPs}$ increased the average area of actin rings from 1.0-fold (control) to 1.8 -fold $(4 \mathrm{mg} / \mathrm{L})$ and 3.1 -fold $(8 \mathrm{mg} / \mathrm{L})$, which subsequently declined from 0.7 -fold $(16 \mathrm{mg} / \mathrm{L})$ to 0.5 -fold $(32 \mathrm{mg} / \mathrm{L})$ and 0.4 -fold $(32 \mathrm{mg} / \mathrm{L})$. Similarly, the average number of nuclei per OC also peaked at 56.97 $(8 \mathrm{mg} / \mathrm{L})$ and declined to $9.94(64 \mathrm{mg} / \mathrm{L})$. Collectively, these results indicate that $\mathrm{CeO}_{2} \mathrm{NPs}$ modulates mature $\mathrm{OC}$ formation in a bidirectional manner. 


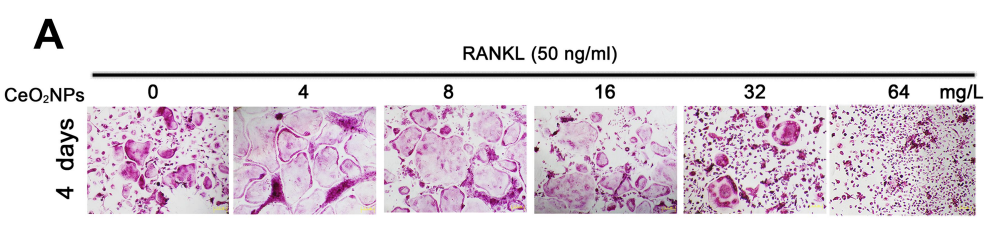

D

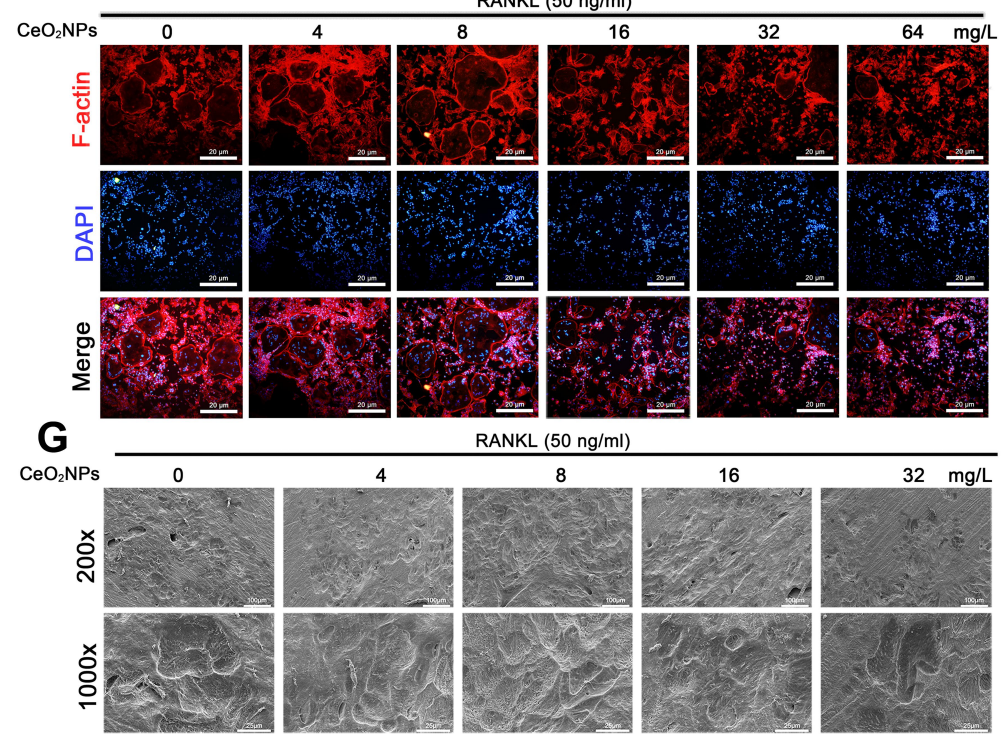

B

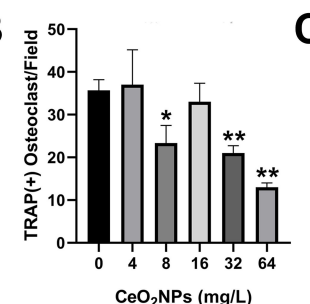

E

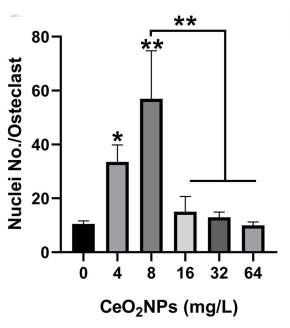

H

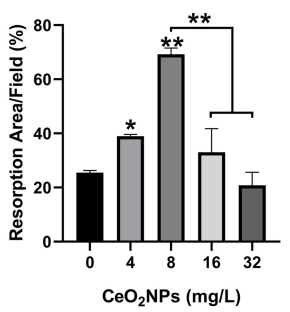

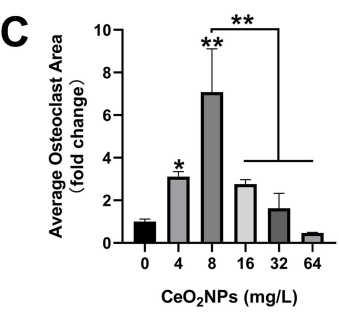

$\mathbf{F}$

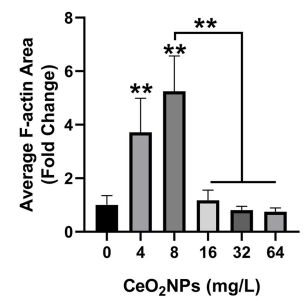

Figure $3 \mathrm{CeO}_{2} \mathrm{NPs}$ modulate RANKL-dependent osteoclastogenesis in vitro by facilitating osteoclast formation at lower concentrations and inhibiting osteoclastogenesis at higher concentrations.

Notes: (A) Representative images of TRAP staining. BMMs were stimulated with RANKL $(50 \mathrm{ng} / \mathrm{mL})$ for 4 days in the absence or presence of various concentrations of $\mathrm{CeO}_{2} \mathrm{NPs}$. Scale bar $=8 \mu \mathrm{M}$. (B) Quantification of TRAP-positive multinucleated osteoclasts that were treated with different concentrations of CeO ${ }_{2} \mathrm{NPs}$ for 4 days. (C) Quantification of the average area of TRAP-positive multinucleated osteoclasts in different groups. (D) Representative images of increased F-actin ring formation in osteoclasts that were treated with lower concentrations of $\mathrm{CeO}_{2} \mathrm{NPs}(4$ and $8 \mathrm{mg} / \mathrm{L}$ ) and impaired F-actin ring formation in osteoclasts that were treated with higher concentrations of $\mathrm{CeO}_{2} \mathrm{NPs}(16,32$, and $64 \mathrm{mg} / \mathrm{L})$. Scale bar $=20 \mu \mathrm{M}$. (E) Quantification of the number of nuclei per osteoclast. (F) Quantification of the relative area of the F-actin ring of osteoclasts. (G) Representative SEM images of bone resorption after treatment with different concentrations of $\mathrm{CeO}_{2} \mathrm{NPs}$ for 14 days. Scale bar $=100 \mu \mathrm{M}$ (H) Quantification of resorbed bone slice area in the different groups. All bar graphs are presented as the mean \pm SD. *Indicates $p<0.05$ compared with the control group $(0$ $\mathrm{mg} / \mathrm{L}, \mathrm{RANKL}+$ ). **Indicates $\mathrm{p}<0.01$ compared with the control group $(0 \mathrm{mg} / \mathrm{L}, \mathrm{RANKL}+$ ).

\section{$\mathrm{CeO}_{2} \mathrm{NPs}$ Modulated Osteoclast Resorptive Activity}

To further validate the effects of $\mathrm{CeO}_{2} \mathrm{NPs}$ on the bone resorptive activity of OCs, we performed bone resorption tests using bovine bone slices. In contrast to the resorptive function of the control, the bone resorptive function of OCs was enhanced at lower concentrations (from $4 \mathrm{mg} / \mathrm{L}$ to $8 \mathrm{mg} / \mathrm{L}$ ) of $\mathrm{CeO}_{2} \mathrm{NPs}$, whereas higher concentrations (from $16 \mathrm{mg} / \mathrm{L}$ to $64 \mathrm{mg} / \mathrm{L}$ ) led to decreased resorptive function (Figure 3G). Resorption area analysis (Figure 3H) showed that the percentage resorption area per field increased from $25.48 \% \pm 0.79 \%(0 \mathrm{mg} / \mathrm{L})$ to $38.94 \% \pm$ $0.66 \%(4 \mathrm{mg} / \mathrm{L})$ and $69.23 \% \pm 2.36 \%(8 \mathrm{mg} / \mathrm{L})$ and then declined to $33.01 \% \pm 8.72 \%(16 \mathrm{mg} / \mathrm{L})$ and $20.85 \% \pm$ $4.81 \%(32 \mathrm{mg} / \mathrm{L})$. These results further confirmed that $\mathrm{CeO}_{2} \mathrm{NPs}$ modulate the resorptive activity of OCs in a bidirectional manner.

\section{$\mathrm{CeO}_{2} \mathrm{NPs}$ Increased ROS Levels in BMMs During Osteoclastogenesis}

According to previous studies, ROS play a crucial role in the initiation of osteoclastogenesis; ROS act as intracellular messenger molecules to activate the downstream MAPK and NF- $\mathrm{KB}$ signaling pathways and then initiate osteoclastogenesis. $\mathrm{CeO}_{2} \mathrm{NPs}$ are well known for their ROS modulating ability. To verify the ROS modulation effects of $\mathrm{CeO}_{2}$ NPs in osteoclastogenesis, we determined the ROS level in BMMs under the stimulation of RANKL and various concentrations of $\mathrm{CeO}_{2} \mathrm{NPs}$ using a sensitive intracellular ROS probe, DCFH-DA. As shown in Figure 4A, the average ROS level of BMMs that were pretreated with different concentrations of $\mathrm{CeO}_{2} \mathrm{NPs}(0,8,16,32$, and $64 \mathrm{mg} / \mathrm{L})$ increased in a dose-dependent manner after treatment with RANKL for 2 days. Similar results were found when we performed intracellular ROS measurements using flow cytometry in 
A

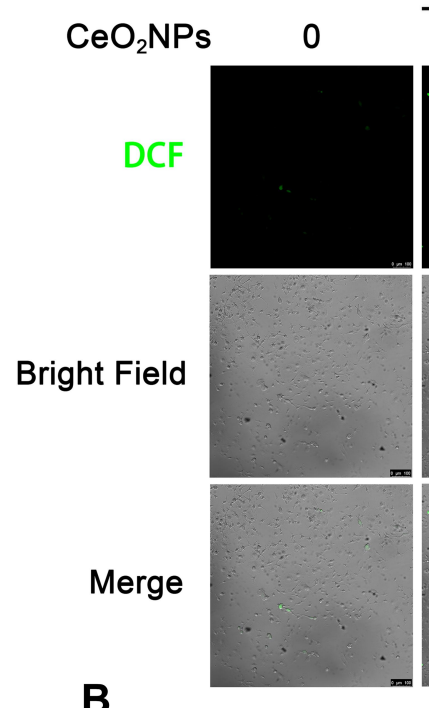

B

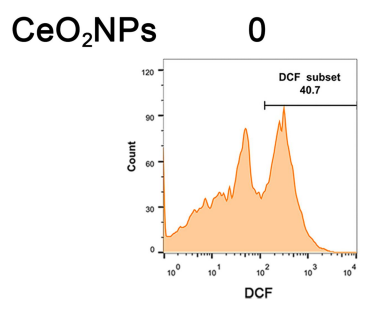

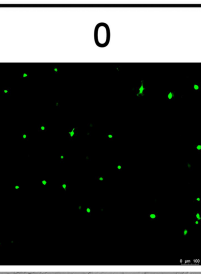
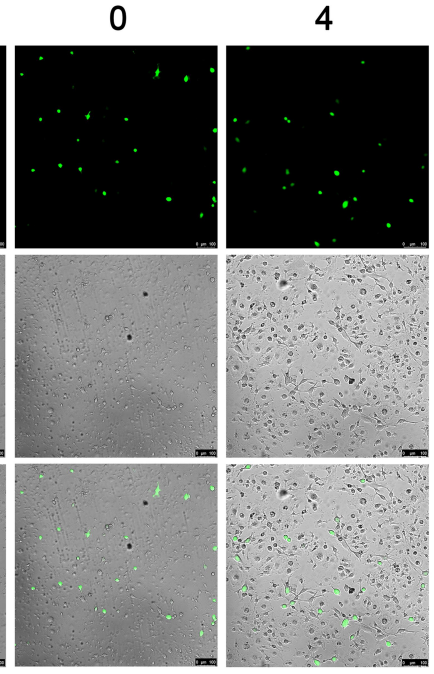

RANKL $(50 \mathrm{ng} / \mathrm{ml})$

8
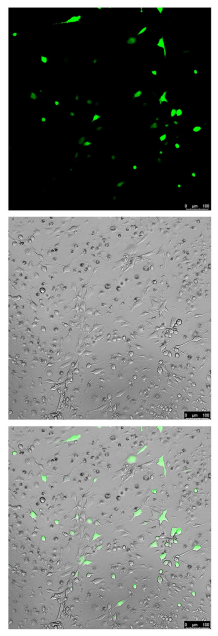

RANKL $(50 \mathrm{ng} / \mathrm{ml})$
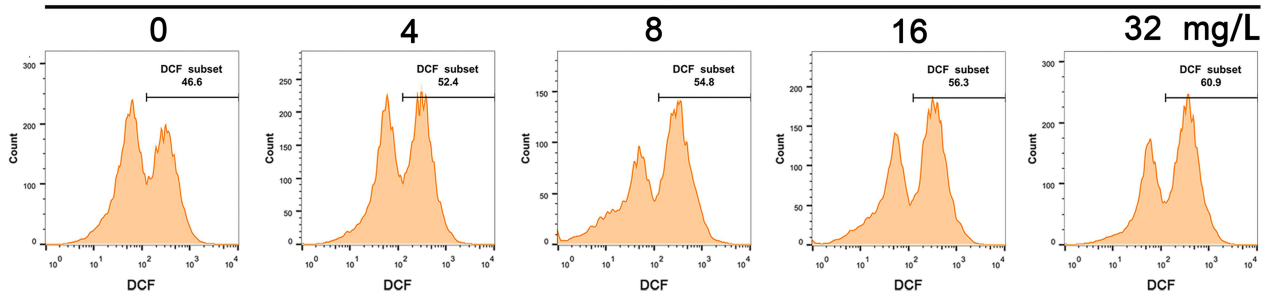

Figure $4 \mathrm{CeO}_{2} \mathrm{NP}$ stimulation increases the intracellular ROS level in BMMs during osteoclastogenesis.

Notes: (A) Representative confocal images of RANKL-induced intracellular ROS generation in BMMs with or without pretreatment with CeO ${ }_{2} \mathrm{NPs}$. BMMs were pretreated with or without $\mathrm{CeO}_{2} \mathrm{NPs}$ and stimulated with or without RANKL for 2 days. BMMs were probed with the ROS-sensitive probe DCFH-DA. Intracellular ROS were detected in the form of fluorescent DCF. Scale bar $=100 \mu \mathrm{M}$. (B) Intracellular ROS generation in $\mathrm{BMMs}$ with or without pretreatment with CeO ${ }_{2} \mathrm{NPs}$ was detected by flow cytometry. BMMs were pretreated with various concentrations of $\mathrm{CeO}_{2} \mathrm{NPs}$, dyed with DCFH-DA, removed from the culture plate with $0.25 \%$ trypsin and stimulated with or without RANKL for 10 min before flow cytometry analysis.

BMMs that were treated with RANKL for 10 min (Figure 4B). The increasing dose of $\mathrm{CeO}_{2} \mathrm{NPs}$ increased the percentage of the high ROS subset of BMMs from $46.7 \%$ to $61.0 \%$ after stimulation with RANKL. Collectively, these results indicate that $\mathrm{CeO}_{2} \mathrm{NP}$ treatment increases the intracellular ROS level of BMMs in the early and middle stages of RANKL-dependent osteoclastogenesis.

\section{$\mathrm{CeO}_{2} \mathrm{NPs}$ Modulate the Acidification Process in OCs}

During osteoclastogenesis, RANKL stimulation upregulates the gene expression of carbonic anhydrase II (CAII), which produces a large amount of $\mathrm{H}^{+}$and decreases the $\mathrm{pH}$ of the cytoplasm of OCs. $\mathrm{H}^{+}$is further pumped into the resorption compartment to maintain an acidic environment, which is vital for the resorption function of osteoclasts. ${ }^{31}$ Moreover, an acidic cellular environment induces the production of ROS by $\mathrm{CeO}_{2}$ NPs. ${ }^{16,33,34,41}$ We detected the acidification-related gene expression of CAII by qPCR (Figure 5A). CAII was significantly upregulated by lower concentrations of $\mathrm{CeO}_{2} \mathrm{NPs}(4,8$, and $16 \mathrm{mg} / \mathrm{L})$. We also measured the intracellular $\mathrm{pH}$ of BMMs and OCs under stimulation with various concentrations of $\mathrm{CeO}_{2} \mathrm{NPs}$ and RANKL on day 2 and day 4 (Figure $5 \mathrm{~B}$ and $\mathrm{C}$ ). The $\mathrm{pH}$ of BMMs on day 2 showed a decreasing trend when the concentrations of $\mathrm{CeO}_{2} \mathrm{NPs}$ increased from 0 to $8 \mathrm{mg} / \mathrm{L}$ and then steadily rose when concentrations of $\mathrm{CeO}_{2} \mathrm{NPs}$ increased from 16 to $64 \mathrm{mg} / \mathrm{L}$. On the 4 th day, OCs that were stimulated with 4,8 , and $16 \mathrm{mg} / \mathrm{L} \mathrm{CeO}_{2} \mathrm{NPs}$ showed significantly lower $\mathrm{pH}$ values $(6.569 \pm 0.01,6.428 \pm 0.10$, $6.49 \pm 0.05)$ compared with those of the vehicle group $(6.795 \pm 0.12)$. However, for the 32 and $64 \mathrm{mg} / \mathrm{L} \mathrm{CeO}_{2} \mathrm{NP}$ groups, the $\mathrm{pH}$ of OCs increased compared with that of the $8 \mathrm{mg} / \mathrm{L}$ group. In conclusion, $\mathrm{CeO}_{2} \mathrm{NPs}$ modulate the acidification of OCs in a bidirectional manner. Relatively lower concentrations of $\mathrm{CeO}_{2} \mathrm{NPs}(4,8$, and $16 \mathrm{mg} / \mathrm{L})$ significantly facilitate acidification of BMMs and OCs during 

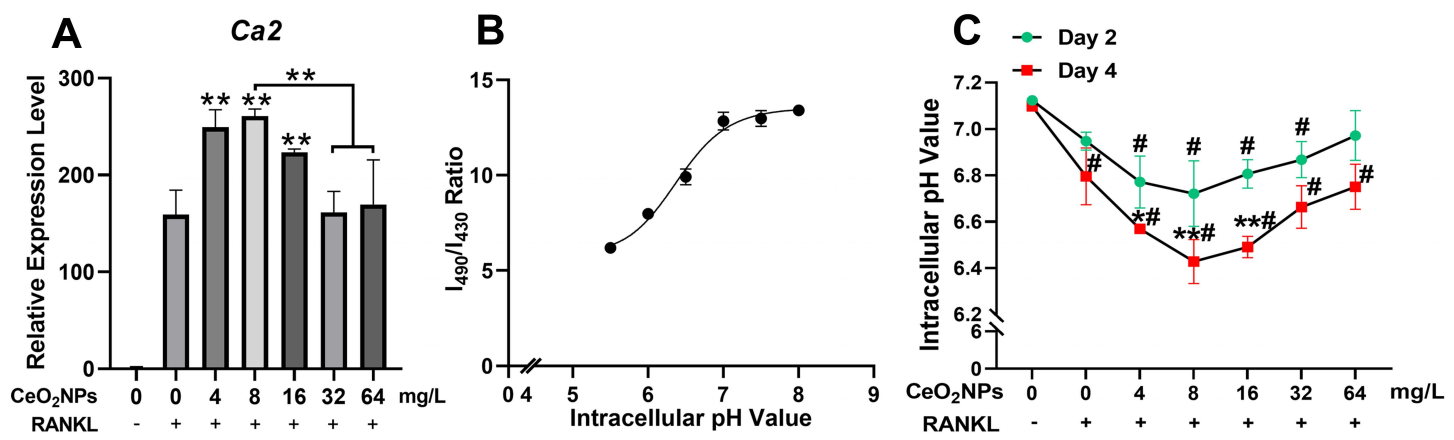

Figure $5 \mathrm{CeO}_{2} \mathrm{NPs}$ bidirectionally modulated intracellular acidification of BMMs during RANKL-dependent osteoclastogenesis.

Notes: $(A)$ qPCR analysis of the gene expression of carbonic anhydrase 2 relative Beta actin in BMMs that were stimulated with or without RANKL in the presence of various concentrations of $\mathrm{CeO}_{2} \mathrm{NPs}$. (B) Calibration plot that correlates the $490 \mathrm{~nm} / 430 \mathrm{~nm}$ fluorescence emission intensity ratio of BCECF-AM upon excitation at $530 \mathrm{~nm}$ to $\mathrm{pH}$. (C) Intracellular $\mathrm{pH}$ of BMMs and $\mathrm{OC}$ were stimulated with various concentrations of $\mathrm{CeO}_{2} \mathrm{NPs}$ and RANKL for 2 days and 4 days. All bar and line graphs are presented as the mean \pm SD. " Indicates $p<0.05$ compared with the control group $(0 \mathrm{mg} / \mathrm{L}, \mathrm{RANKL}-)$. *Indicates $\mathrm{p}<0.05$ compared with the vehicle group $(0 \mathrm{mg} / \mathrm{L}, \mathrm{RANKL}+)$. $* *$ Indicates $\mathrm{p}<0.01$ compared with the vehicle group $(0 \mathrm{mg} / \mathrm{L}$, RANKL+).

osteoclastogenesis, but this effect tended to diminish with a further increase in $\mathrm{CeO}_{2} \mathrm{NP}$ concentrations.

\section{Bidirectional Regulation of Osteoclast-Specific Gene Expression and Signaling Pathways by $\mathrm{CeO}_{2} \mathrm{NPs}$}

To further investigate the mechanisms of the bidirectional regulatory effects of $\mathrm{CeO}_{2} \mathrm{NPs}$ on osteoclastogenesis, we determined the expression levels of several osteoclastspecific genes using qRT-PCR and detected activation of the osteoclastogenesis-related signaling pathway by Western blotting. As shown in Figure 6A, expression of Acp5, Ctsk, DCSTAMP, Traf6, C-Fos, and Calcr in BMMs was upregulated in the presence of RANKL. These genes were further upregulated by lower concentrations of $\mathrm{CeO}_{2}$ NPs compared with those of the vehicle group, peaking at
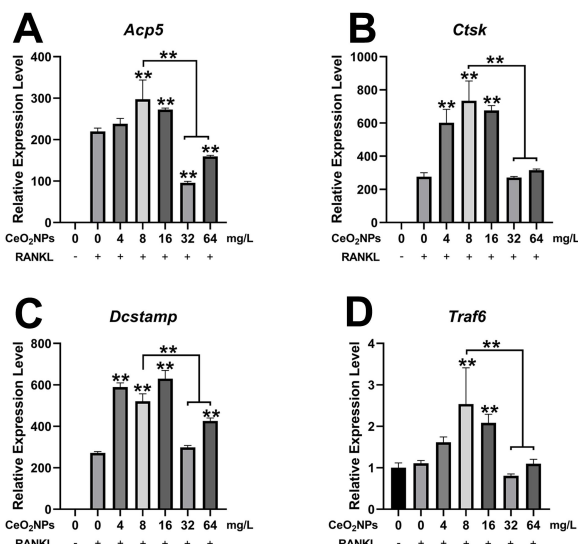

rana
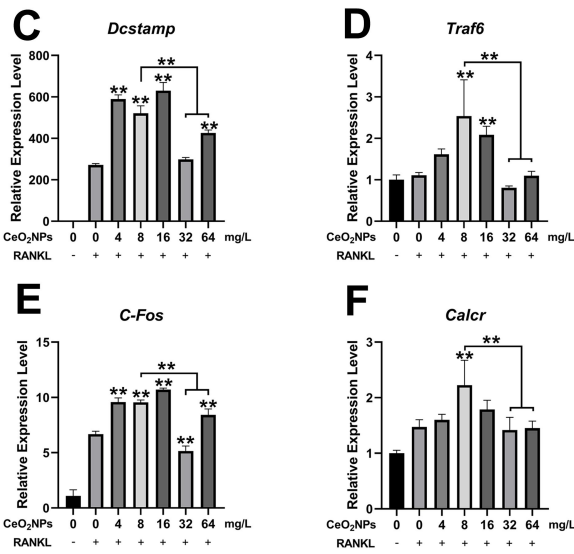

F
G

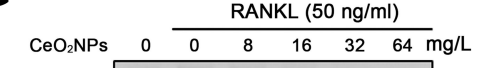

p-ERK

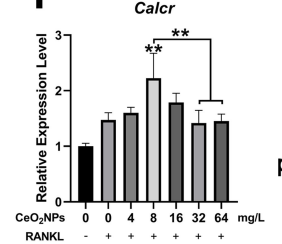

ERK

p-JNK

JNK

p-P38

P38

GAPDH

I
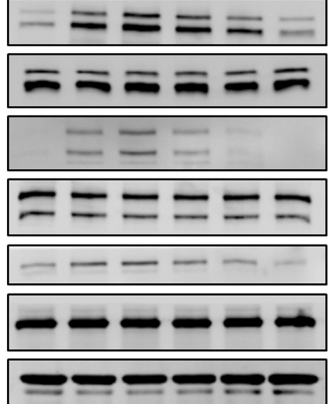

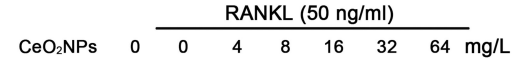

NFATc1

LaminB

p-NFATc1

GAPDH
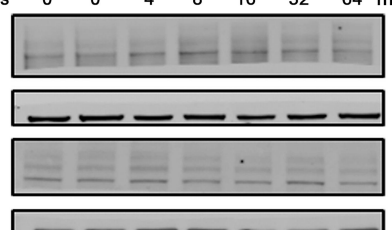

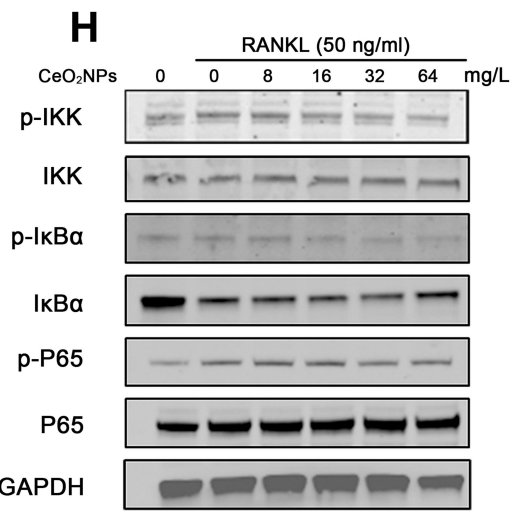

Figure $6 \mathrm{CeO}_{2} \mathrm{NPs}$ modulate osteoclast-specific gene expression via up- or downregulating the MAPK pathway, NF- $\mathrm{kB}$ pathway, and Nfatcl signaling in a concentrationdependent manner.

Notes: (A-F) qPCR analysis of expression of the osteoclast-specific genes Acp5, Ctsk, Dcstamp, Traf6, C-fos, and Calcr relative to Beta-actin in BMMs that were stimulated with RANKL for 4 days in the presence of various concentrations of $\mathrm{CeO}_{2} \mathrm{NPs}$ ( $\mathrm{n}=3$ per group). ( $\mathbf{G}$ and $\mathbf{H}$ ) Western blot analysis of the MAPK and NF- $\mathrm{kB}$ pathways. BMMs were pretreated with different concentrations of $\mathrm{CeO}_{2} \mathrm{NPs}$ for $24 \mathrm{~h}$ before stimulation with RANKL for 20 min. (I) Western blot of the translocation of dephosphorylated $\mathrm{Nfatcl}$ into the nuclei of BMMs. BMMs were pretreated with different concentrations of $\mathrm{CeO}_{2} \mathrm{NPs}$ for $24 \mathrm{~h}$ before stimulation with RANKL for 40 min. All bar graphs are presented as the mean $\pm \mathrm{SD}$. **Indicates $\mathrm{p}<0.01$ compared with the vehicle group $(0 \mathrm{mg} / \mathrm{L}, \mathrm{RANKL}+$ ). 
$8 \mathrm{mg} / \mathrm{L}$. With increasing in $\mathrm{CeO}_{2} \mathrm{NPs}$ concentrations, nearly all related genes were downregulated in comparison with those in the $8 \mathrm{mg} / \mathrm{L} \mathrm{CeO}_{2} \mathrm{NPs}$ group.

Activation of the NF- $\mathrm{KB}$ and MAPK signaling pathways is closely related to RANKL-dependent osteoclastogenesis. Therefore. We pretreated BMMs with various concentrations of $\mathrm{CeO}_{2} \mathrm{NPs}$ for $24 \mathrm{~h}$ and then determined

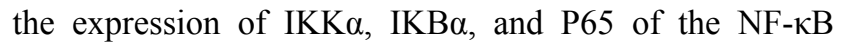
signaling pathway and ERK, JNK, and P38 of the MAPK signaling pathway after stimulating pretreated BMMs with RANKL for 20 min (Figure 6B and C). The results indicated that phosphorylation of $\operatorname{IKK} \alpha, \operatorname{IKB} \alpha$, and P65 relative to total IKK $\alpha, \operatorname{IKB} \alpha$, and P65 and phosphorylation of ERK, JNK, and P38 relative to total ERK, JNK, and P38 increased at $4 \mathrm{mg} / \mathrm{L}$, peaked at $8 \mathrm{mg} / \mathrm{L}$, and subsequently declined from $16 \mathrm{mg} / \mathrm{L}$ to $64 \mathrm{mg} / \mathrm{L}$. These results were consistent with the former characterization of $\mathrm{OC}$ formation, suggesting that the MAPK and NF- $\mathrm{KB}$ pathways were both engaged in the $\mathrm{CeO}_{2} \mathrm{NP}$-mediated bidirectional modulation of osteoclast activation. In addition, the expression level of a master osteoclast-related transcription factor, Nfatc1, in BMMs that were stimulated with RANKL for 40 min (Figure 6D) was determined. We found that expression of the active nonphosphorylated form of Nfatc1 increased in the presence of RANKL and treatment with $\mathrm{CeO}_{2} \mathrm{NPs}$ at concentrations no greater than $8 \mathrm{mg} / \mathrm{L}$ and subsequently decreased with $\mathrm{CeO}_{2} \mathrm{NP}$ treatment at concentrations from $16 \mathrm{mg} / \mathrm{L}$ to $64 \mathrm{mg} / \mathrm{L}$. Collectively, these results revealed the underlying mechanisms during the bidirectional modulation of osteoclasts by $\mathrm{CeO}_{2} \mathrm{NPs}$.

\section{$\mathrm{CeO}_{2} \mathrm{NPs}$ Facilitated Apoptosis of BMMs During Osteoclastogenesis}

The abovementioned results suggested that $\mathrm{CeO}_{2} \mathrm{NPs}$ dosedependently enhanced intracellular ROS levels in BMMs, while overloading intracellular ROS may lead to increased apoptosis and dysfunction of BMMs. To validate this, TUNEL staining and annexin V-FITC/propidium iodide (PI) double staining were performed to detect BMM apoptosis after treatment with various concentrations of $\mathrm{CeO}_{2}$ NPs $(0,4,8,16,32$, and $64 \mathrm{mg} / \mathrm{L})$ with or without RANKL for 2 days. As shown in Figure $7 \mathrm{~A}$ and $\mathrm{C}, \mathrm{CeO}_{2} \mathrm{NPs}$ increased the number of apoptotic cells in a dosedependent manner. Few apoptotic cells were observed in the 0,4 , and $8 \mathrm{mg} / \mathrm{L} \mathrm{CeO}_{2} \mathrm{NP}$ groups, whereas more apoptotic cells were detected in the high concentration groups
$(16,32$, and $64 \mathrm{mg} / \mathrm{L})$. Flow cytometry analysis of Annexin V-FITC/PI double staining indicated that early apoptosis and total apoptosis rates of BMMs increased as the concentrations of $\mathrm{CeO}_{2} \mathrm{NPs}$ increased.

These results were also confirmed by qRT-PCR (Figure 8A) and Western blotting (Figure 8B). The expression of proapoptotic Bad and Bax was upregulated, especially at high $\mathrm{CeO}_{2}$ concentrations (32 and $64 \mathrm{mg} / \mathrm{L}$ ), and the antiapoptotic gene Bcl-2 was downregulated as the concentration of $\mathrm{CeO}_{2} \mathrm{NPs}$ increased. Western blot analysis also showed that the expression of $\mathrm{Bcl} 2$ decreased and the proapoptotic protein cleaved caspase-3/caspase-3 ratio increased as the concentration of $\mathrm{CeO}_{2} \mathrm{NPs}$ increased. These results suggest that high concentrations of $\mathrm{CeO}_{2}$ NPs lead to cell apoptosis and dysfunction, thus inhibiting osteoclast formation.

\section{Discussion}

Recent years have witnessed the rapid development of nanomaterial applications in medicine. $\mathrm{CeO}_{2} \mathrm{NPs}$ are among the first batch of nanomaterials and have been explored in medical use. $\mathrm{CeO}_{2} \mathrm{NPs}$ perform catalasemimetic, superoxide dismutase-mimetic and peroxidasemimetic activities in biological environments. Their robust, stable, regenerative and multiple enzymatic reactivities have been extensively tested in various types of cells and several pathological processes, such as neural injury, infection, systemic inflammation, cancer, and bone tissue engineering. ${ }^{10,41-43}$ Generally, $\mathrm{CeO}_{2} \mathrm{NPs}$ are regarded as potent ROS scavengers that protect cells from oxidative stress damage. Extensive studies have explored the effects of $\mathrm{CeO}_{2} \mathrm{NPs}$ on the viability of BMSCs, osteoblasts, chondrocytes and BMSCs during osteoblastic differentiation. Some reports indicated that cell viability and osteoblastic differentiation were enhanced by $\mathrm{CeO}_{2} \mathrm{NPs}^{18-22,44,45}$ However, these studies indicated that $\mathrm{CeO}_{2} \mathrm{NPs}$ increase ROS production in acidic intercellular environments and exhibit bidirectional regulatory effects on osteoclast differentiation, which suggests that the application of $\mathrm{CeO}_{2} \mathrm{NPs}$ should take into account the cellular environment and dosedependent effects.

$\mathrm{CeO}_{2} \mathrm{NPs}$ with a diameter of $20 \mathrm{~nm}$ were used in this study. According to previous studies, surface valence state and size are important factors in manipulating intracellular catalytic activity. $\mathrm{CeO}_{2} \mathrm{NPs}$ with a higher $\mathrm{Ce}^{4+} / \mathrm{Ce}^{3+}$ surface valence ratio usually showed catalase-mimetic activity, which depletes intracellular $\mathrm{H}_{2} \mathrm{O}_{2}$ and protects cells from oxidative stress. ${ }^{5,6}$ In contrast, $\mathrm{CeO}_{2} \mathrm{NPs}$ with a higher 


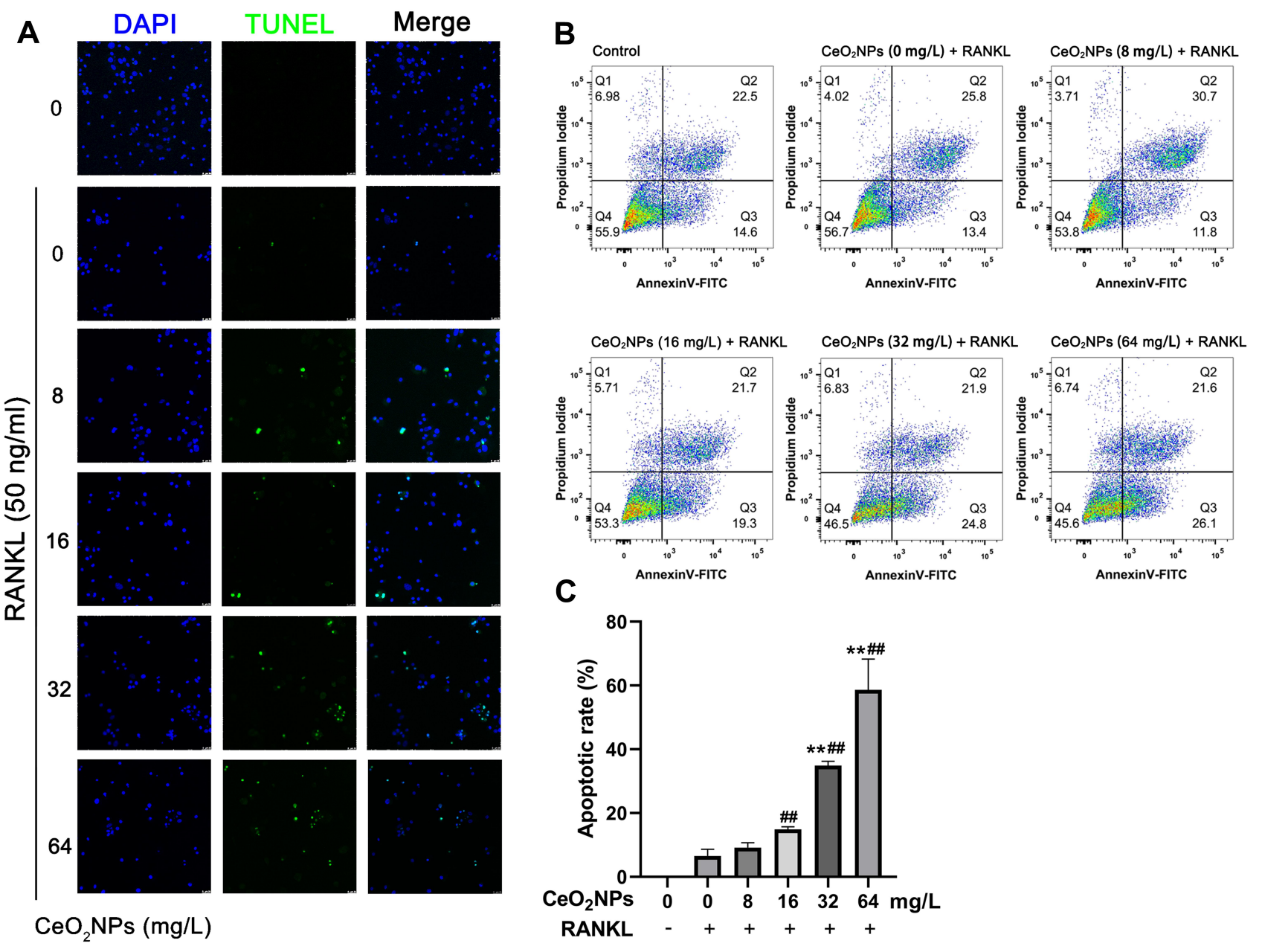

Figure $7 \mathrm{CeO}_{2} \mathrm{NPs}$ increased the apoptosis of BMMs during RANKL-dependent osteoclastogenesis.

Notes: (A) Representative confocal images of the TUNEL assay of BMMs that were pretreated with different concentrations of CeO $2 \mathrm{NPs}(0,8$, 16,32 , and 64 mg/L) for 24 $\mathrm{h}$ and stimulated with or without RANKL for two days. Scale bar $=25 \mu \mathrm{M}$. (B) Representative flow cytometry images of Annexin V-FITC/PI double staining of BMMs that were pretreated with different concentrations of $\mathrm{CeO}_{2} \mathrm{NPs}(0,8,16,32$, and $64 \mathrm{mg} / \mathrm{L})$ for $24 \mathrm{~h}$ and stimulated with or without RANKL for two days. (C) Quantification of the apoptotic rate of BMMs (TUNEL-positive nuclei relative to total nuclei). All bar graphs are presented as the mean \pm SD. ${ }^{\prime \prime}$ Indicates $p<0.0$ I compared with the control group ( $0 \mathrm{mg} / \mathrm{L}, \mathrm{RANKL}-)$. $* *$ Indicates $\mathrm{p}<0.0 \mathrm{l}$ compared with the vehicle group $(0 \mathrm{mg} / \mathrm{L}, \mathrm{RANKL}+)$.

surface $\mathrm{Ce}^{3+} / \mathrm{Ce}^{4+}$ ratio tended to show SOD-mimetic activities in the intracellular microenvironment and catalyze the disproportionate reaction of $\mathrm{O}^{2-}$ to produce excessive $\mathrm{H}_{2} \mathrm{O}_{2}$, which harms cell viability and leads to cell dysfunction. ${ }^{5,8,46,47}$ The XPS results revealed that the relative $\mathrm{Ce}^{4+}$ content was $73 \%$ and that of $\mathrm{Ce}^{3+}$ was $27 \%$. The surface oxygen content was approximately $19.67 \%$. The diameter of $\mathrm{CeO}_{2} \mathrm{NPs}$ was approximately $20 \mathrm{~nm}$, which was suitable for cell internalization, which was further validated by TEM observations. In addition, before cell experiments, we used ESR to determine the antioxidative effects of $\mathrm{CeO}_{2} \mathrm{NPs}$ in acellular environments by measuring $\mathrm{O}^{2-}$ and $\mathrm{H}_{2} \mathrm{O}_{2}$ generated by hypoxanthine and xanthine oxidase. Our results indicated that the $\mathrm{CeO}_{2} \mathrm{NPs}$ used in this study efficiently reduced the production of $\mathrm{O}^{2-}$ and $\mathrm{H}_{2} \mathrm{O}_{2}$.
Within the bone marrow, macrophages proliferate and fuse into giant multinucleated mature osteoclasts, which are responsible for bone resorption and bone remodeling. ${ }^{48}$ First, we tested the cytotoxic effects of $\mathrm{CeO}_{2} \mathrm{NPs}$ on BMMs and found that BMM viability was not obviously impaired in the presence of up to $64 \mathrm{mg} / \mathrm{L} \mathrm{CeO}{ }_{2} \mathrm{NPs}_{\text {after }}$ two days of culture. Therefore, we chose concentrations of $\mathrm{CeO}_{2} \mathrm{NPs}$ below $64 \mathrm{mg} / \mathrm{L}$ to perform subsequent experiments. Interestingly, although the number of OCs per field decreased in the $8 \mathrm{mg} / \mathrm{L}$ group compared with that of the control group, which may be attributed to the extensive fusion of BMMs into more giant OCs at $8 \mathrm{mg} / \mathrm{L}$, the results from the osteoclast formation assay and actin ring formation assay indicated that lower concentrations of $\mathrm{CeO}_{2} \mathrm{NPs}$ facilitated more giant osteoclast formation. However, this facilitating effect reversed the inhibitory 

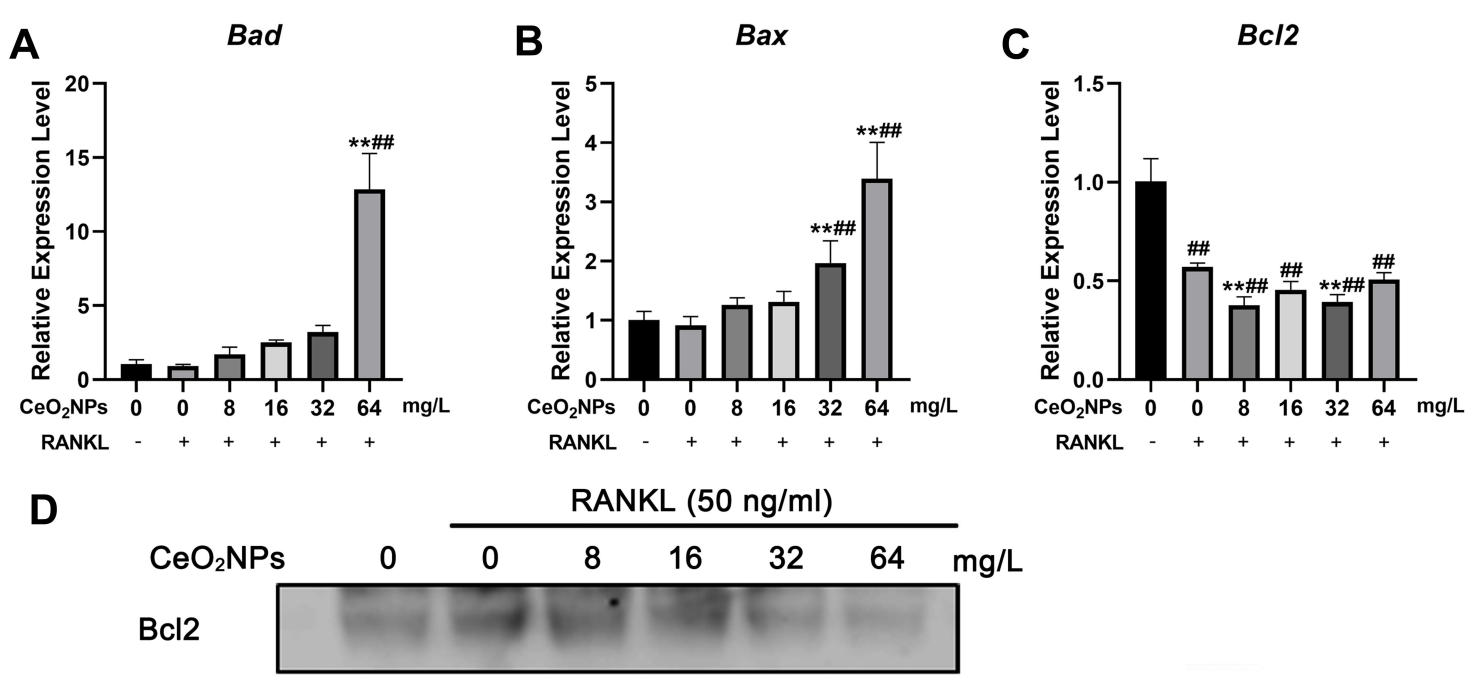

GAPDH

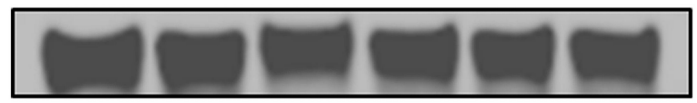

\section{cleaved- caspase 3}

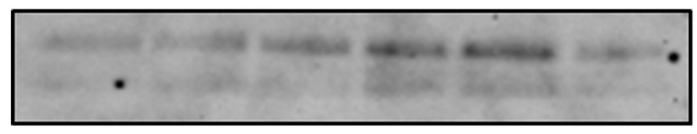

Caspase 3

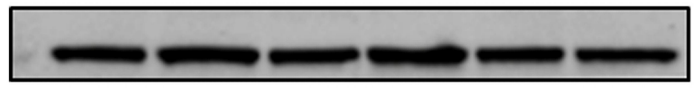

GAPDH

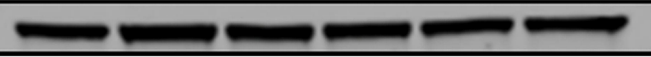

Figure 8 Effects of CeO2NPs on apoptosis-related gene expression.

Notes: (A-C) qPCR analysis of expression of apoptosis-related genes, including Bax, Bad, and Bcl2. (D) Western blot analysis of Bcl2, cleaved caspase 3 and caspase 3. BMMs were pretreated with various $\mathrm{CeO}_{2} \mathrm{NPs}(8,16,32$, and $64 \mathrm{mg} / \mathrm{L})$ for $24 \mathrm{~h}$ and then stimulated with or without RANKL for 2 days. All bar graphs are presented as the mean \pm SD. ${ }^{\#}$ Indicates $p<0.01$ compared with the control group $(0 \mathrm{mg} / \mathrm{L}$, RANKL-). **Indicates $\mathrm{p}<0.0 \mathrm{l}$ compared with the vehicle group $(0 \mathrm{mg} / \mathrm{L}$, RANKL+).

effect, as demonstrated by the decreased osteoclast number and area with increasing concentrations of $\mathrm{CeO}_{2} \mathrm{NPs}$. This intriguing result showed the bidirectional effects of $\mathrm{CeO}_{2}$ NPs on osteoclast formation and bone resorption.

The MAPK and NF-kB signaling pathways are two classical signaling pathways in the activation of osteoclasts. ${ }^{48}$ Under RANKL stimulation, TNF receptorassociated factor 6 (Traf6) is activated and then activates the downstream protein kinase TAK1, which subsequently phosphorylates ERK and IKK $\alpha$. Phosphorylated ERK and $\mathrm{IKK} \alpha$ further activate the MAPK and NF- $\mathrm{KB}$ signaling pathways and finally activate the essential transcription factor Nfatc1 for osteoclastogenesis. ${ }^{49}$ ROS directly or indirectly activate the MAPK and NF- $\mathrm{KB}$ signaling pathways. ${ }^{50-58}$ Previous studies demonstrated that $\mathrm{H}_{2} \mathrm{O}_{2}$ induces reversible oxidation of cysteine residues of IKK $\alpha$ / $\beta$ and phosphorylation of $I \kappa B \alpha$, which subsequently activates the NF- $\kappa B$ signaling pathway. ${ }^{54,55}$ ROS also induce the dislocation of Trx from apoptosis signal-regulating kinase 1 (ASK1), which then phosphorylates JNK and p38 and finally leads to activation of the MAPK signaling pathway. ${ }^{56-58}$ Our data showed that pretreatment with lower $\mathrm{CeO}_{2} \mathrm{NPs}(8 \mathrm{mg} / \mathrm{L})$ enhanced RANKL-induced phosphorylation of ERK, JNK, and P38, thus achieving its facilitating effects, whereas the phosphorylation of ERK, JNK, and P38 decreased slightly as the $\mathrm{CeO}_{2} \mathrm{NP}$ concentrations further rose. Similar trends were also observed in NF-KB activation. Nfatc1 is a master transcription factor that regulates downstream osteoclast-specific gene expression. The Western blotting results showed that lower $\mathrm{CeO}_{2} \mathrm{NP}$ concentrations ( 4 and $8 \mathrm{mg} / \mathrm{L}$ ) increased the dephosphorylation of Nfatc1 and facilitated its nuclear translocation, while higher $\mathrm{CeO}_{2} \mathrm{NP}$ concentrations ( 16 and $64 \mathrm{mg} / \mathrm{L}$ ) decreased activation of Nfatc1. This result demonstrated that $\mathrm{CeO}_{2}$ NPs generate ROS, activate the downstream MAPK and $\mathrm{NF}-\kappa \mathrm{B}$ pathways and finally activate Nfatc1 or directly interact with Nfatc1 in the early stage of osteoclastogenesis. We also measured the downstream genes that are regulated by Nfatc1, including Acp 5, Ctsk, DCSTAMP, Traf6, C-Fos, and $C a l c r$, and showed an increasing trend in the expression 
of these genes in the lower $\mathrm{CeO}_{2} \mathrm{NP}$ concentration groups $(4,8 \mathrm{mg} / \mathrm{L})$ and a decreasing trend in expression in the higher $\mathrm{CeO}_{2} \mathrm{NP}$ concentration group. These results also validated the bidirectional modulatory effects of $\mathrm{CeO}_{2} \mathrm{NPs}$ on osteoclast activation.

Next, explored the underlying mechanism of the bidirectional effects of $\mathrm{CeO}_{2} \mathrm{NPs}$ on osteoclastogenesis. RANKL induces intracellular ROS production in BMMs. Hence, we determined ROS production using DCFH-DA as an intracellular ROS probe. Measurement of the ROSpositive cell ratio indicated that intracellular ROS production in BMMs on day 0 and day 2 was increased by RANKL and further enhanced by $\mathrm{CeO}_{2} \mathrm{NPs}$ in a dose-dependent manner. This oxidative effect of $\mathrm{CeO}_{2} \mathrm{NPs}$ contradicts our previous ROS scavenging results in the acellular oxidative system. A distinct characteristic of BMMs and OCs is their abundance of acidic lysosomes, which are responsible for antigen phagocytosis and bone resorption. It has been reported that $\mathrm{CeO}_{2} \mathrm{NPs}$ facilitate ROS production in acidic cellular microenvironments, such as various cancer cells. Because of the Warburg effect, cancer cells tend to generate energy through glycolysis even in an abundant $\mathrm{O}_{2}$ environment and produce much lactate, resulting in a comparatively acidic cytoplasm. Wason MS. found that $\mathrm{CeO}_{2} \mathrm{NPs}$ enhanced ROS production in pancreatic cancer cells and increased the sensitization of pancreatic cancer to radiation therapy. ${ }^{16}$ Researchers attribute the oxidative effects of $\mathrm{CeO}_{2} \mathrm{NPs}$ in acidic environments to protons that block the redox cycling from $\mathrm{Ce}^{3+}$ to $\mathrm{Ce}^{4+}$, resulting in excessive toxic $\mathrm{H}_{2} \mathrm{O}_{2}$ production in cells. Our TEM results showed that some $\mathrm{CeO}_{2} \mathrm{NPs}$ were distributed in lysosomes after internalization by BMMs. We attribute the increase in early ROS production in BMMs that were stimulated by RANKL to the intracellular distribution of $\mathrm{CeO}_{2} \mathrm{NPs}$ in acidic lysosomes. Moreover, with activation of osteoclastogenesis by RANKL, carbonic anhydrase was highly upregulated in BMMs and further catalyzed the production of protons, which were then pumped into the acidic compartment to form the acidic bone resorption environment $(\mathrm{pH}$ : 4.7-6.8). ${ }^{59}$ Our qPCR results showed that carbonic anhydrase II was significantly upregulated in the lower $\mathrm{CeO}_{2} \mathrm{NP}$ concentration groups compared with those of the vehicle group. In addition, intracellular $\mathrm{pH}$ measurements suggested that the intracellular $\mathrm{pH}$ of OCs that were treated with lower concentrations of $\mathrm{CeO}_{2} \mathrm{NPs}$ was significantly lower than that of OCs in the vehicle groups, which could account for the increase in intracellular ROS in OCs during the middle and late stages of osteoclastogenesis. In conclusion, intracellular distribution in lysosomes and acidification triggered by RANKL stimulation are initiating factors that contribute to increased ROS production by $\mathrm{CeO}_{2} \mathrm{NPs}$. ROS production increased by $\mathrm{CeO}_{2} \mathrm{NPs}$ further facilitated the osteoclastogenesis and acidification process of OCs, which further increased the production of ROS by $\mathrm{CeO}_{2} \mathrm{NPs}$ in a positive feedback manner. Although previous ROS measurements suggested that $\mathrm{CeO}_{2} \mathrm{NPs}$ dosedependently increase intracellular ROS production in BMMs under the stimulation of RANKL, higher concentrations of $\mathrm{CeO}_{2} \mathrm{NPs}$ inhibited osteoclastogenesis compared with lower concentrations of $\mathrm{CeO}_{2} \mathrm{NPs}$. We hypothesized that excessive $\mathrm{CeO}_{2} \mathrm{NP}$ internalization and subsequent ROS production leads to disturbances in cell structure and cell dysfunction and ultimately, cell apoptosis. The TUNEL assay showed that $\mathrm{CeO}_{2} \mathrm{NPs}$ resulted in late-stage apoptosis of BMMs in a dose-dependent manner. This proapoptotic effect was further confirmed by Annexin V-FITC/PI double staining, which indicated that higher concentrations of $\mathrm{CeO}_{2} \mathrm{NPs}$ facilitate not only late-stage apoptosis but also early-stage apoptosis of BMMs during RANKL-dependent osteoclastogenesis. We then measured the expression of several classic genes that are related to apoptosis through qPCR and Western blotting. The results indicated that a high $(64 \mathrm{mg} / \mathrm{L})$ concentration of $\mathrm{CeO}_{2} \mathrm{NP}$ significantly increased the expression of $B a x$ at the transcriptional level and that the expression of $\mathrm{Bcl} 2$ was decreased at both the transcriptional and protein levels. The expression of cleaved caspase-3/caspase-3 was upregulated in the 16 and $32 \mathrm{mg} / \mathrm{L}$ concentration groups. These results indicate that high $\mathrm{CeO}_{2} \mathrm{NP}$ treatment resulted in cell apoptosis during osteoclastogenesis. We hypothesize that the different outcomes of the CCK-8 and apoptosis experiments can be accounted for by the acidification and ROS production triggered by RANKL. Enhanced ROS production by $\mathrm{CeO}_{2}$ NPs cooperates with the acidification of BMMs during osteoclastogenesis, as we observed in the $8 \mathrm{mg} / \mathrm{L}$ group, leading to the upregulated expression of carbonic anhydrase and the strongest osteoclast formation. Importantly, in the highest $\mathrm{CeO}_{2} \mathrm{NP}$ concentration group (64 mg/L), most gene expression was inhibited, which might be due to excessive internalization of $\mathrm{CeO}_{2} \mathrm{NPs}$ disrupting the normal gene expression pattern of BMMs. This was again confirmed by TEM observation, showing the absence of normal organelle structure in BMMs that were filled with $\mathrm{CeO}_{2} \mathrm{NPs}$. We also found that $\mathrm{CeO}_{2} \mathrm{NPs}$ were internalized into the nucleus, which might disrupt normal cell metabolism and gene expression. 


\section{Conclusion}

This study demonstrated that $\mathrm{CeO}_{2} \mathrm{NPs}$ with a comparatively increased surface $\mathrm{Ce}^{4+} / \mathrm{Ce}^{3+}$ ratio bidirectionally modulate RANKL-dependent osteoclastogenesis by enhancing intracellular ROS production, which enhances activation of the MAPK and NF- $\mathrm{KB}$ pathways, followed by activation of Nfatc1 and downstream osteoclastogenesis-related gene expression at lower $\mathrm{CeO}_{2} \mathrm{NP}$ concentrations. The cellular distribution of $\mathrm{CeO}_{2} \mathrm{NPs}$ in lysosomes and increasing acidification of cell plasma may be the factors that initiate and facilitate increased intracellular ROS production by $\mathrm{CeO}_{2} \mathrm{NPs}$. In contrast, increased concentrations of $\mathrm{CeO}_{2} \mathrm{NPs}$ led to the obvious disturbance of cell structure and cell apoptosis. These findings reminded us that the use of $\mathrm{CeO}_{2} \mathrm{NPs}$ as drug delivery vehicles or antioxidant components needs to be given more attention regarding the cellular environment and dose-dependent effects.

\section{Ethics Approval}

All animal experiments were reviewed and approved by the Animal Ethical Committee of Shanghai Ninth People's Hospital. The approval number is SH9H-2019-A719-1.

\section{Author Contributions}

K.Y. and J.M. contributed equally to this work. All authors made a significant contribution to the work reported, whether that is in the conception, study design, execution, acquisition of data, analysis and interpretation, or in all these areas; took part in drafting, revising or critically reviewing the article; gave final approval of the version to be published; have agreed on the journal to which the article has been submitted; and agree to be accountable for all aspects of the work.

\section{Funding}

This study was supported by the Shanghai Science and Technology Development Fund (18DZ2291200, 18441902700) and National Natural Science Foundation for Young Scientist of China (81902230).

\section{Disclosure}

The authors report no conflicts of interest in this work.

\section{References}

1. Dutta P, Pal S, Seehra MS, Shi Y, Eyring EM, Ernst RD. Concentration of $\mathrm{Ce} 3+$ and oxygen vacancies in cerium oxide nanoparticles. Chem Mater. 2006;18(21):5144-5146. doi:10.1021/cm061580n
2. Celardo I, Pedersen JZ, Traversa E, Ghibelli L. Pharmacological potential of cerium oxide nanoparticles. Nanoscale. 2011;3 (4):1411-1420. doi:10.1039/c0nr00875c

3. Mullins DR. The surface chemistry of cerium oxide. Surf Sci Rep. 2015;70(1):42-85. doi:10.1016/j.surfrep.2014.12.001

4. Deshpande S, Patil S, Kuchibhatla SV, Seal S. Size dependency variation in lattice parameter and valency states in nanocrystalline cerium oxide. Appl Phys Lett. 2005;87(13):133113. doi:10.1063/ 1.2061873

5. Pirmohamed T, Dowding JM, Singh S, et al. Nanoceria exhibit redox state-dependent catalase mimetic activity. Chem Commun (Camb). 2010;46(16):2736-2738. doi:10.1039/b922024k

6. Nicolini V, Gambuzzi E, Malavasi G, et al. Evidence of catalase mimetic activity in $\mathrm{Ce}(3+) / \mathrm{Ce}(4+)$ doped bioactive glasses. $J$ Phys Chem B. 2015;119(10):4009-4019. doi:10.1021/jp511737b

7. Li Y, He X, Yin JJ, et al. Acquired superoxide-scavenging ability of ceria nanoparticles. Angew Chem Int Ed Engl. 2015;54 (6):1832-1835. doi:10.1002/anie. 201410398

8. Korsvik C, Patil S, Seal S, Self WT. Superoxide dismutase mimetic properties exhibited by vacancy engineered ceria nanoparticles. Chem Commun (Camb). 2007;(10):1056-1058. doi:10.1039/b615134e

9. Tian Z, Li J, Zhang Z, Gao W, Zhou X, Qu Y. Highly sensitive and robust peroxidase-like activity of porous nanorods of ceria and their application for breast cancer detection. Biomaterials. 2015;59:116-124. doi:10.1016/j.biomaterials.2015.04.039

10. Selvaraj V, Nepal N, Rogers S, et al. Inhibition of MAP kinase/ NF-kB mediated signaling and attenuation of lipopolysaccharide induced severe sepsis by cerium oxide nanoparticles. Biomaterials. 2015;59:160-171. doi:10.1016/j.biomaterials.2015.04.025

11. Pagliari F, Mandoli C, Forte G, et al. Cerium oxide nanoparticles protect cardiac progenitor cells from oxidative stress. ACS Nano. 2012;6(5):3767-3775. doi:10.1021/nn2048069

12. Kwon HJ, Cha MY, Kim D, et al. Mitochondria-targeting ceria nanoparticles as antioxidants for alzheimer's disease. ACS Nano. 2016;10(2):2860-2870. doi:10.1021/acsnano.5b08045

13. Wu L, Liu G, Wang W, et al. Cyclodextrin-modified $\mathrm{CeO}(2)$ nanoparticles as a multifunctional nanozyme for combinational therapy of psoriasis. Int J Nanomedicine. 2020;15:2515-2527. doi:10.2147/IJN. S246783

14. Zand Z, Khaki PA, Salihi A, et al. Cerium oxide NPs mitigate the amyloid formation of $\alpha$-synuclein and associated cytotoxicity. Int J Nanomedicine. 2019;14:6989-7000. doi:10.2147/IJN.S220380

15. Alili L, Sack M, von Montfort C, et al. Downregulation of tumor growth and invasion by redox-active nanoparticles. Antioxid Redox Signal. 2013;19(8):765-778. doi:10.1089/ars.2012.4831

16. Wason MS, Colon J, Das S, et al. Sensitization of pancreatic cancer cells to radiation by cerium oxide nanoparticle-induced ROS production. Nanomedicine. 2013;9(4):558-569. doi:10.1016/j. nano.2012.10.010

17. Renu G, Rani VVD, Nair SV, Subramanian KRV, Lakshmanan V-K. Development of cerium oxide nanoparticles and its cytotoxicity in prostate cancer cells. Adv Sci Lett. 2012;6(1):17-25. doi:10.1166/ asl.2012.3312

18. Li J, Wen J, Li B, et al. Valence state manipulation of cerium oxide nanoparticles on a titanium surface for modulating cell fate and bone formation. Adv Sci (Weinh). 2018;5(2):1700678. doi:10.1002/ advs. 201700678

19. Li K, Xie Y, You M, Huang L, Zheng X. Plasma sprayed cerium oxide coating inhibits $\mathrm{H} 2 \mathrm{O} 2$-induced oxidative stress and supports cell viability. J Mater Sci Mater Med. 2016;27(6):100. doi:10.1007/ s10856-016-5710-9

20. You M, Li K, Xie Y, Huang L, Zheng X. The effects of cerium valence states at cerium oxide coatings on the responses of bone mesenchymal stem cells and macrophages. Biol Trace Elem Res. 2017;179(2):259-270. doi:10.1007/s12011-017-0968-4 
21. Li K, Yu J, Xie Y, You M, Huang L, Zheng X. The effects of cerium oxide incorporation in calcium silicate coating on bone mesenchymal stem cell and macrophage responses. Biol Trace Elem Res. 2017;177 (1):148-158. doi:10.1007/s12011-016-0859-0

22. Li K, Xie Y, You M, Huang L, Zheng X. Cerium oxide-incorporated calcium silicate coating protects MC3T3-E1 osteoblastic cells from H2O2-induced oxidative stress. Biol Trace Elem Res. 2016;174 (1):198-207. doi:10.1007/s12011-016-0680-9

23. Li K, Shen Q, Xie Y, You M, Huang L, Zheng X. Incorporation of cerium oxide into hydroxyapatite coating protects bone marrow stromal cells against $\mathrm{H} 2 \mathrm{O} 2$-induced inhibition of osteogenic differentiation. Biol Trace Elem Res. 2018;182(1):91-104. doi:10.1007/s12011-017-1066-3

24. Labudzynskyi D, Zholobak N. Effects of cerium (IV) oxide nanoparticles on RAW 264.7 cells activity and RANKL-stimulated osteoclastogenesis. Conference paper presented at: Modern aspects of Biochemistry and Biotechnology; May 23; 2018; Kyiv.

25. Lee NK, Choi YG, Baik JY, et al. A crucial role for reactive oxygen species in RANKL-induced osteoclast differentiation. Blood. 2005;106(3):852-859. doi:10.1182/blood-2004-09-3662

26. Callaway DA, Jiang JX. Reactive oxygen species and oxidative stress in osteoclastogenesis, skeletal aging and bone diseases. J Bone Miner Metab. 2015;33(4):359-370. doi:10.1007/s00774-015-0656-4

27. Srinivasan S, Koenigstein A, Joseph J, et al. Role of mitochondrial reactive oxygen species in osteoclast differentiation. Ann N Y Acad Sci. 2010;1192(1):245-252. doi:10.1111/j.1749-6632.2009.05377.x

28. Agidigbi TS, Kim C. Reactive oxygen species in osteoclast differentiation and possible pharmaceutical targets of ROS-mediated osteoclast diseases. Int J Mol Sci. 2019;20(14):3576. doi:10.3390/ijms20143576

29. Zhang J, Wang X, Vikash V, et al. ROS and ROS-mediated cellular signaling. Oxid Med Cell Longev. 2016;2016:4350965. doi:10.1155/ 2016/4350965

30. Gibon E, Lu LY, Nathan K, Goodman SB. Inflammation, ageing, and bone regeneration. J Orthop Translat. 2017;10:28-35. doi:10.1016/j. jot.2017.04.002

31. Rousselle AV, Heymann D. Osteoclastic acidification pathways during bone resorption. Bone. 2002;30(4):533-540. doi:10.1016/S87563282(02)00672-5

32. Asati A, Kaittanis C, Santra S, Perez JM. pH-tunable oxidase-like activity of cerium oxide nanoparticles achieving sensitive fluorigenic detection of cancer biomarkers at neutral pH. Anal Chem. 2011;83 (7):2547-2553. doi:10.1021/ac102826k

33. Alpaslan E, Yazici H, Golshan NH, Ziemer KS, Webster TJ. pHdependent activity of dextran-coated cerium oxide nanoparticles on prohibiting osteosarcoma cell proliferation. ACS Biomater Sci Eng. 2015;1(11):1096-1103. doi:10.1021/acsbiomaterials.5b00194

34. Asati A, Santra S, Kaittanis C, Nath S, Perez JM. Oxidase-like activity of polymer-coated cerium oxide nanoparticles. Angew Chem Int Ed. 2009;48(13):2308-2312. doi:10.1002/anie.200805279

35. Wason MS, Zhao J. Cerium oxide nanoparticles: potential applications for cancer and other diseases. Am J Transl Res. 2013;5(2):126-131.

36. Patterson AL. The scherrer formula for X-ray particle size determination. Phys Rev. 1939;56(10):978-982. doi:10.1103/PhysRev.56.978

37. Zhou F, Mei J, Yuan K, Han X, Qiao H, Tang T. Isorhamnetin attenuates osteoarthritis by inhibiting osteoclastogenesis and protecting chondrocytes through modulating reactive oxygen species homeostasis. $J$ Cell Mol Med. 2019;23(6):4395-4407. doi:10.1111/jcmm.14333

38. Behbahan ISS, McBrian MA, Kurdistani SK. A protocol for measurement of intracellular pH. Bio-Protocol. 2014;4(2):e1027. doi:10.21769/BioProtoc. 1027

39. Li J, Xiang L, Jiang X, et al. Investigation of bioeffects of G protein-coupled receptor 1 on bone turnover in male mice. J Orthop Translat. 2017;10:42-51. doi:10.1016/j.jot.2017.05.001

40. Mei J, Zhou F, Qiao H, Li H, Tang T. Nerve modulation therapy in gouty arthritis: targeting increased SFRP2 expression in dorsal root ganglion regulates macrophage polarization and alleviates endothelial damage. Theranostics. 2019;9(13):3707-3722. doi:10.7150/thno.33908
41. Gao Y, Chen K, Ma J-L GF. Cerium oxide nanoparticles in cancer. Onco Targets Ther. 2014;7:835-840. doi:10.2147/OTT.S62057

42. Naz S, Beach J, Heckert B, et al. Cerium oxide nanoparticles: a 'radical' approach to neurodegenerative disease treatment. Nanomedicine (Lond). 2017;12(5):545-553. doi:10.2217/nnm-20160399

43. Xiang J, Li J, He J, et al. Cerium oxide nanoparticle modified scaffold interface enhances vascularization of bone grafts by activating calcium channel of mesenchymal stem cells. ACS Appl Mater Interfaces. 2016;8(7):4489-4499. doi:10.1021/acsami.6b00158

44. Naganuma T, Traversa E. The effect of cerium valence states at cerium oxide nanoparticle surfaces on cell proliferation. Biomaterials. 2014;35(15):4441-4453. doi:10.1016/j.biomaterials. 2014.01.074

45. Li K, Shen Q, Xie Y, You M, Huang L, Zheng X. Incorporation of cerium oxide into hydroxyapatite coating regulates osteogenic activity of mesenchymal stem cell and macrophage polarization. $J$ Biomater Appl. 2017;31(7):1062-1076. doi:10.1177/08853282 16682362

46. Pulido-Reyes G, Rodea-Palomares I, Das S, et al. Untangling the biological effects of cerium oxide nanoparticles: the role of surface valence states. Sci Rep. 2015;5(1):15613. doi:10.1038/ srep 15613

47. Chen BH, Stephen Inbaraj B. Various physicochemical and surface properties controlling the bioactivity of cerium oxide nanoparticles. Crit Rev Biotechnol. 2018;38(7):1003-1024. doi:10.1080/07388551. 2018.1426555

48. Boyle WJ, Simonet WS, Lacey DL. Osteoclast differentiation and activation. Nature. 2003;423(6937):337-342. doi:10.1038/ nature 01658

49. Kurotaki D, Yoshida H, Tamura T. Epigenetic and transcriptional regulation of osteoclast differentiation. Bone. 2020;138:115471. doi:10.1016/j.bone.2020.115471

50. Moldogazieva NT, Mokhosoev IM, Feldman NB, Lutsenko SV. ROS and RNS signalling: adaptive redox switches through oxidative/nitrosative protein modifications. Free Radic Res. 2018;52(5):507-543. doi:10.1080/10715762.2018.1457217

51. Jung Y, Kim H, Min SH, Rhee SG, Jeong W. Dynein light chain LC8 negatively regulates NF-kappaB through the redox-dependent interaction with IkappaBalpha. J Biol Chem. 2008;283(35):23863-23871. doi:10.1074/jbc.M803072200

52. Kim HJ, Chang EJ, Kim HM, et al. Antioxidant alpha-lipoic acid inhibits osteoclast differentiation by reducing nuclear factor-kappaB DNA binding and prevents in vivo bone resorption induced by receptor activator of nuclear factor-kappaB ligand and tumor necrosis factor-alpha. Free Radic Biol Med. 2006;40(9):1483-1493. doi:10.1016/j.freeradbiomed.2005.10.066

53. Rezatabar S, Karimian A, Rameshknia V, et al. RAS/MAPK signaling functions in oxidative stress, DNA damage response and cancer progression. J Cell Physiol. 2019;234(9):14951-14965. doi:10.1002/ jcp. 28334

54. Lisse TS, Rieger S. IKK $\alpha$ regulates human keratinocyte migration through surveillance of the redox environment. J Cell Sci. 2017;130 (5):975-988. doi:10.1242/jcs. 197343

55. Takada Y, Mukhopadhyay A, Kundu GC, Mahabeleshwar GH, Singh S, Aggarwal BB. Hydrogen peroxide activates NF-kappa B through tyrosine phosphorylation of I kappa B alpha and serine phosphorylation of p65: evidence for the involvement of I kappa B alpha kinase and Syk protein-tyrosine kinase. J Biol Chem. 2003;278(26):24233-24241. doi:10.1074/jbc.M212389200

56. Kylarova S, Kosek D, Petrvalska O, et al. Cysteine residues mediate high-affinity binding of thioredoxin to ASK1. FEBS J. 2016;283 (20):3821-3838. doi:10.1111/febs.13893

57. Katagiri K, Matsuzawa A, Ichijo H. Regulation of apoptosis signal-regulating kinase 1 in redox signaling. Methods Enzymol. 2010;474:277-288. 
58. Liu J, Chang F, Li F, et al. Palmitate promotes autophagy and apoptosis through ROS-dependent JNK and p38 MAPK. Biochem Biophys Res Commun. 2015;463(3):262-267. doi:10.1016/j.bbrc. 2015.05.042
59. Maeda H, Kowada T, Kikuta J. Real-time intravital imaging of $\mathrm{pH}$ variation associated with osteoclast activity. Nat Chem Biol. 2016;12 (8):579-585. doi:10.1038/nchembio.2096

\section{Publish your work in this journal}

The International Journal of Nanomedicine is an international, peerreviewed journal focusing on the application of nanotechnology in diagnostics, therapeutics, and drug delivery systems throughout the biomedical field. This journal is indexed on PubMed Central, MedLine, CAS, SciSearch ${ }^{\mathbb{R}}$, Current Contents ${ }^{\mathbb{R}} /$ Clinical Medicine, $^{2}$
Journal Citation Reports/Science Edition, EMBase, Scopus and the Elsevier Bibliographic databases. The manuscript management system is completely online and includes a very quick and fair peer-review system, which is all easy to use. Visit http://www.dovepress.com/ testimonials.php to read real quotes from published authors. 